\title{
An improved second generation wave model
}

\author{
Emesto Cactano' \& Valdir Innocentini ${ }^{2}$ \\ 'Centro de Ciencias de la Atmósfera, UNAM \\ (Av. Circuito Exterior s/n, Ciudad Universitaria 04510, México D.F., México) \\ ?Instituto Nacional de Pesquisas Espaciais, MCT \\ (Av. dos Astronautas 1758, 12201-970, São José dos Campos, SP, Brazil)
}

- Abstract: A numerical second-generation sea wave model (SG) is presented and applied to December 1992 events on Mediterranean Sea. The energy advection is performed using a semiLagrangian scheme. The wind sea is generated by surface wind data supplied by a global/limited area atmospheric model or global analysis. The source terms (generation, dissipation and nonlinear interactions) are tuned to fit the empirical Sanders' duration-limited growth curve. An angular relaxation scheme is used in changing wind direction situations by permitting that the energy migrates slowly toward the new wind direction. This is accomplished by a combination of the actual spectrum and that one built by a rapid directional relaxation. One-month SG run testing for December 1992 was performed for the Mediterranean Sea and compared with observational buoy data. Results show the model was able to hindcast unusual wave activity associated to few cyclones, which have affected the area. Comparison with WAM (Komen et. al., 1994) run for the same period presents similar results, which is very encouraging to apply this low computational cost sea wave model for hindcast studies.

- Resumo: Um modelo numérico de ondas oceânicas (SG) é apresentado e aplicado para eventos no Mar Mediterrâneo durante o mês de dezembro de 1992. A advecção de energia utiliza um esquema semi-Lagrangeano. Os ventos em superfície são gerados por modelos atmosféricos global ou de área limitada ou, ainda, por dados atmosféricos de análise global. Os termos fontes (de geração, dissipação e interação não-linear) são ajustados à curva empírica de crescimento de duração limitada, proposta por Sanders. Um esquema de relaxação para situações de variação de direção de vento, que permite que a energia emigra lentamente a nova direção do vento, é proposto. Este esquema combina o espectro real e aquele obtido por um esquema de relaxação direcional rápido. Uma simulação com o SG, para dezembro de 1992 no mar Mediterâneo, foi realizada e os resultados comparados com observações de dados de bóias. Os resultados mostram que o SG é capaz de simular eventos de agitação marítima associados a sistemas frontais que durante o período analisado passaram pela região. Comparado com a simulação feita pelo modelo WAM (Komen et. al., 1994) para os mesmos eventos, mostra que ambos modelos apresentam resultados similares. Portanto o modelo SG pode ser aplicado em estudos de casos e experimentos climáticos com a vantagem de ter um custo computacional relativamente baixo.

- Descriptors: Sea waves, Sea waves model, Wind waves modelling.

- Descritores: Modelo de ondas oceânicas, Ondas oceânicas, Modelo de ondas geradas pelo vento.

\section{Introduction}

Several national meteorological services are presently forecasting sea waves, generated by surface wind using numerical models with boundary conditions provided by atmospheric numerical models.
Potential applications of these model outputs can be classified in two types: 2 to 3 day forecast and hindcast. The wave forecast may help naval operations, coastal protection, estimate oil dispersion caused by accidental leaks and so on. The hindcast involves applications of the sea wave model in extreme meteorological situations occurring during 20-30 years in a determined region and climate 
change studies. The database generated is used to estimate the return period probability of variables, like wave height, peak frequency, wind speed and wind direction. They are very useful in problems related to engineering and exploitating of mineral resources (Alves \& Melo Filho, 1997; Rego \& Melo Filho, 1995).

Significant distinctions concerning the numerical parameterisation of physical processes can be pointed out among existing wave models. Some models are very simple and can operate on microcomputers (Earle, 1989) while others are so complex that their operational implementation depends on large computer resources (WAMDI 1988). Wave models are classified in first, second and third generations. Only main characteristics of these models will be summarised here (a detailed description can be found in SWAMP (1985). hereafter S85).

In first generation models, a twodimensional wave spectrum (frequency-direction) evolves when the wind forcing reaches a saturation level defined by a universal equilibrium distribution (Phillips, 1957). Each spectral component propagates with its own group velocity. They are also referred as decoupled models, since they do not take into account non-lincar interactions among distinct frequencies. In second-generation models the nonlinear interactions are parameterised in order to a certain spectral distribution of energy is reproduced. In general the JONSWAP distribution is the spectral shape assumed (Hasselmann ot al., 1973). These models are called as parametrical models (Hasselmann et cl., 1976). In so called hybrid model (S85) the swell is explicitly represented by the spectrum and the wind sea by parameters. And finally non-linear interactions are parametrized in the third generation models (Hasselmann and Hasselmann 1985: Komen et al., 1994). Some tuning parameters are however introduced, in order to the spectral distribution and migration of energy resemble theoretical and experimental results (Komen et al. 1984; S85). This procedure implies the computation of five-dimensional Boltzmann integrals. Exact computation of these expressions demands much computing time; therefore more efficient numerical methods have been proposed (Hasselmann \& Hasselmann 1985). The third generation WAM model (Komen et al., 1994) uses an exact non-linear transfer source function parameterisation in order to save computer time.

Although second generation wave models

have from various shortcomings, they are still attractive in hindcast and even operational applications, since a much more modest computer capability is required. Their main failures are detected in situations with rapid wind variation (Young et al., 1987). Essentially, in many models of this kind, a large part of the spectrum responds instantaneously to a wind shift. Analysis of observations obtained by Allender et al. (1983) reports though, the low frequency energy tends to align slowly with the new wind direction. These results are confirmed by observations and numerical models by Gunther et al. (1981), Holthuijsen (1987), Masson (1990), and van Vledder \& Holthuijsen (1993). Another failure is related to situations exhibiting a sudden decrease in wind speed. Part of the spectrum, identified as swell after a wind decreasing, stays untouched by the non-linear interactions, while the other part is immediatcly displaced towards a new peak frequency. In both cases mentioned above, a discontinuity appears between the swell (old wind sea) and the new windsea rangers in the frequency spectrum. In order to overcome the shortcoming due to rapid changing wind direction several approaches have been suggested. Gunther et al. (1981) proposed a prognostic equation for the lag between the wind and average wave direction in a parametric model. In his equation a constant depending on the frequency controls the time relaxation of the wave direction. In the model presented by Janssen et al. (1984) (hereafter GONO model) the wind-sea spectrum is also not aligned with the wind direction, but with an average direction computed using swell and wind sea. In the second-generation model proposed by Guillaume (1990) the discontinuity generated by building the wind sea aligned with the wind direction is avoided. In her model the minimum frequency is a function of the direction. When the wind-sea angular spreading is performed in this model, some regions of the twodimensional domain may have swell and wind sea at same time.

In this work, a non-parametric numerical wave model (SG) is proposed for applications in hindcast studies. A gradual directional relaxation scheme is presented to adjust the wind-sea direction smoothly. The approach consists into defining a weight function that emulates a gradual migration of cnergy toward the peak frequency and wind dircetion. This can be done by a linear combination between the present spectrum and that one which would result from an abrupt migration of energy. Section 2 describes the model. The duration-limited growth experiment carried out by $\mathrm{S} 85$ is reproduced here using $S G$, and a comparative discussion of results is presented in section 3. In section 4 various wave activity episodes associated to cyclones occurred over the Mediterranean were simulated and compared with buoy data and WAM model simulations. The wind data forcing was from ECMWF (European Centre for Medium Range Weather Forecasts) analysis, which provided the input wind energy for SG and WAM at 3 hours intervals. Finally in section 5 summarises the main results and conclusions. 


\section{Model description}

The SG is based on the energy balance equation. The rate of the wave spectral variance for a spectral component with frequency $f$ at time $t, E(x$.

$0, f, l)$ is given by:

$$
\frac{d E}{d t} \equiv \frac{\partial E}{\partial t}+c_{s g} \nabla E=-E \nabla c_{s g}-\frac{\partial}{\partial}\left[\left(c_{g} \cdot \nabla\right) E\right]+S_{m}+S_{d s}+S_{n i}
$$

Where $f$ is the frequency $\left(\mathrm{s}^{-1}\right), \theta$ the direction (rad), $x=(x, y)$ the spatial position (m), the time (s).

Right hand side (rhs) terms represent the shoaling. refraction and energy input due to the wind action; wave breaking dissipation, and non-linear interactions, respectively. $c_{z}$ is the group velocity

and $\nabla \equiv m(s / a, c / c y)$, where $m$ is the map factor. The Eq. (1) is numerically integrated in its discretized form. The $\mathrm{SG}$ uses 36 directions $n=1,2, \ldots, 36$, with 13 frequencies corresponding to periods of $1,2,3,4$. $5,6,7,8,10,13,16,20$ and $25 \mathrm{~s}$ to represent numerically the wave spectrum. The time step is 30 minutes. The spatial increments $x$ and $y$ are specified in each numerical experiment. The numerical approach used for the computation of rhs terms of Eq. (1) will be described as follows:

\section{Advection and shoaling terms} given by

$$
\frac{\partial E}{\partial t}=-\nabla\left(\underset{\sim}{c_{g}} E\right)=-\underset{\sim}{c_{g}} \cdot \nabla E+E \underset{\sim}{\nabla} \underbrace{}_{g} \cdot
$$

Where the 3 rd and 4 th terms represent the advection and shoaling, respectively. Both terms can be computed simultaneously by the 2nd term. However, in this model a scmi-Lagrangian scheme is adopted, which implies they are treated numerically separated. The shoaling effect in one direction is

$$
-E\left(\nabla \cdot c_{x}\right)=-m E\left(\begin{array}{c}
\partial c_{x} \\
\partial x^{x}
\end{array} \cos \theta+\frac{\partial c_{x}}{\partial y} \sin \theta\right)
$$

The spatial derivatives are approximated by the 2 nd order finite difference sclieme. The group velocity depends on the ocean depth $h(x, y)$ and frequency. It is given by:

$$
c_{g}=\left[1+\begin{array}{c}
2 k h \\
\sinh (2 k h)
\end{array}\right]\left[\begin{array}{l}
g \\
k
\end{array} \tanh (k h)\right]^{0.5},
$$

where $k$ is the wavenumber. The dispersion equation yields a relation between $f$ and $k$

$$
(2 \pi f)^{2}=g k \tanh (k h) .
$$

The numerical solution advection term is given by

$E^{n+1}=E^{n}\left(\underset{\sim}{x-x_{d}}\right), \quad x_{\sim}=\int_{\sim}^{(n+1) \Delta t} \underset{\sim g}{c} d t \approx \underset{\sim g}{c}\left(x_{\sim}\right) \Delta t$

With $n$ and $n+1$ represent the time levels. After having computed $x$ the value of $E\left(x-x_{1}\right)$ is obtained by a nine points polynomial interpolation given by Carnahan et al. (1969). Following Bates and McDonald (1982), the central point is the nearest to $\underset{\sim}{x}-x_{d}$. Depending on $\Delta x$ and $\left|c_{g}\right|$ values, it can

occur that none of the nine points selected by the interpolation formula are where the advection is being computed. In this case and when $c_{g}$ has a large

spatial variation, the approximation used in Eq. (2) must be avoided. For the frequency range employed here, the maximum group velocity is around $70 \mathrm{kmh}^{-1}$ (corresponding to the wave period of $25 \mathrm{~s}$ ). For $\mathrm{t}=$ $0.5 \mathrm{~h},\left|x_{d}\right| \approx 35 \mathrm{~km}$. Therefore some care is necessary for $A x$ smaller than $70 \mathrm{~km}$. The main attraction of this scheme resides on its unconditional stability.

Two types of boundary conditions are used depending on the numerical simulation. When $x-x_{d}$ is located out of domain then: i) $E^{n !}=0$ or

ii) $E^{n+1}$ points outside of domain are set to equal to boundary value points.

\section{Refiaction}

Golding (1983) provides the refraction scheme adopted here. Namely

$$
-\frac{\partial}{\partial \theta}\left[\left(c_{x} \cdot \nabla\right) E\right]_{\theta}=
$$

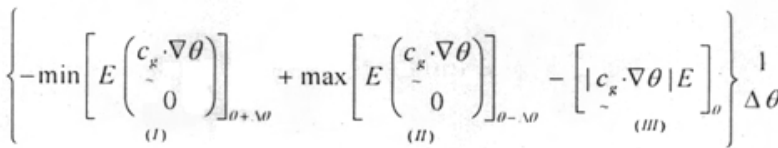

$$
\text { where }
$$




$$
c_{g} \cdot \nabla \theta=\frac{\left|c_{g}\right|}{k}\left[\begin{array}{l}
\partial h \\
\partial x
\end{array} \sin \theta-\frac{\partial h}{\partial y} \cos \theta\right] A(k, h),
$$

with

$$
A(k, H)=\frac{k^{2} \operatorname{sech}^{2}(k h)}{\tanh (\kappa h)+k H \operatorname{sech}^{2}(k h)} .
$$

Figure 1 illustrates how the scheme works. Note that $c_{g} \cdot \nabla \theta$ is proportional to $\sin \delta$, where $\delta$ is the angle between $\nabla h$ and the direction 0 . Then $c_{g} \cdot \nabla \theta$ is positive (negative) to the right (left) of $\nabla h$.

The following properties can then be observed:

- Term (I) is zero if $0<(0+\Delta \theta)<\pi$ - contribution comes from $\theta-\Delta \theta$;

- Term (II) is zero if $\pi<(\theta-\Delta \theta)<2 \pi$ - contribution comes from $\theta+\Delta \theta$;

- Terms (I), (II) and (III) are zero for $\theta$ along $\nabla_{7}$;

- Term (III) is zero for $\theta$ along - $\nabla h$.

This scheme is upstream, and the stability is guaranteed whenever

$\left|\mathrm{c}_{\mathrm{g}}\right| \leq \Delta \theta$

\section{Non-linear interactions}

Amongst other features the non-linear interactions source term accounts for the energy migration toward the peak frequency (not included yet) and wind direction. The angular spreading of energy will be considered in the next sub-section. The conservative energy transfer is performed on the wind-sea domain, in order to preserve a prescribed spectral shape. Suppose the wind direction is $\theta_{11}$. It can then be defined,

$$
\begin{aligned}
& E_{n}^{0}(f)=\int_{\nu_{n} \pi_{2}}^{n_{1}+\pi_{2}} E d O \text {, frequency wind-sea energy: } \\
& E_{\mathrm{w}}^{f}(\theta)=\int_{f_{\mathrm{um}}}^{r} E d f \text {, directional wind-sea energy }
\end{aligned}
$$

and

$$
\ddot{E}_{w}=\int_{f_{\text {min }}}^{\infty} E_{w}{ }_{w} d f \quad \text { total wind-sea energy. }
$$

Where $f_{\text {min }}$ is the minimum frequency for the wind-sea domain. The wind-sea energy spectral distribution adopted in SG is the Kruseman spectrum (Janssen $e t$ al., 1984). Namely,

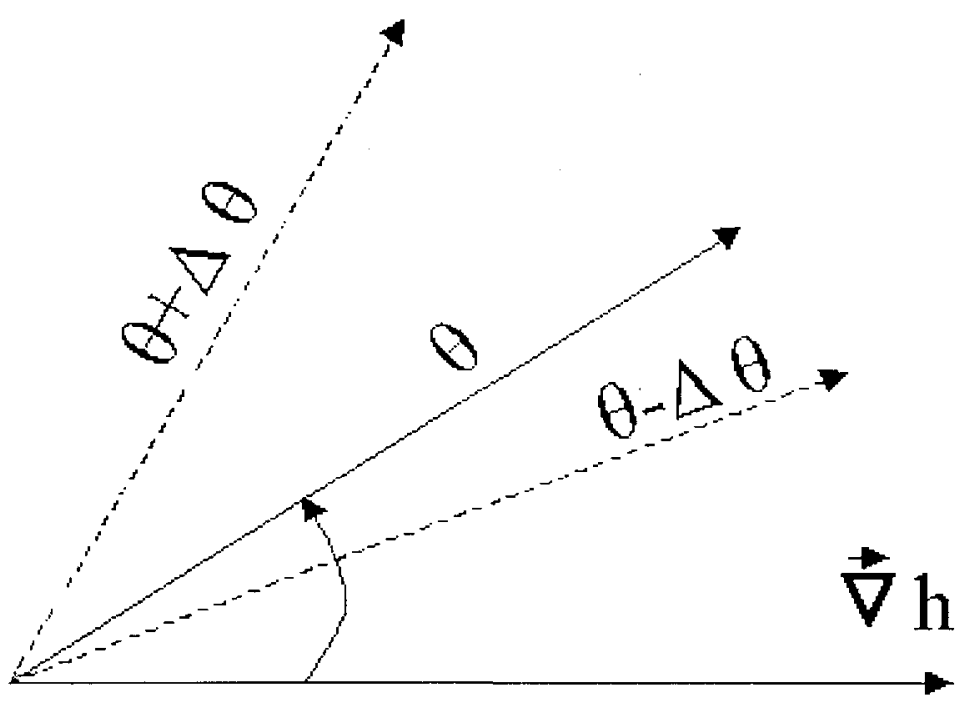

\section{SHALLOW}

Fig. 1. Diagram illustrating the energy refraction from the direction $0-\Delta 0$ to direction 0 . 


$$
E_{w}^{0}=\left\{\begin{array}{ccc}
0 & \text { if } & f<f_{\text {min }} \\
\alpha g^{2} \times{ }^{1} \times \frac{f-f_{\min }}{f-f_{\min }} & \text { if } & f_{\min }<f<f_{p}, \\
(2 \pi)^{4} & & \\
f_{p}^{3} g^{2} \times \frac{1}{f^{3}} & \text { if } & f_{p}<f \\
(2 \pi)^{4} \times f
\end{array}\right.
$$

With $g-9.8 \mathrm{~ms}^{-2}$ and $f_{p}$ is the peak frequency. The parameter $\alpha$ depends on the spectrum development stage:

$$
\alpha=4.93 \times 10^{-3} \xi^{-1.944}, \quad \xi=\left(\bar{E}_{w} E_{w \max }\right)^{0.25} .
$$

Sanders et al. (1981) determined empirically that the total wind-sea energy in the fully developed stage is,

$\bar{E}_{w_{\max }}=\left(U_{10}^{2} \beta(4 g)\right)^{2}$

With $U_{10}$ is the wind speed at $10 \mathrm{~m}$ height above ocean surface. $\beta$ is the growth-rate parameter, varying from 0.14 to 0.22 in JONSWAP data. We have chosen $\beta=0.22$ for SG. The peak frequency dependence on the development stage, is given by,

$f_{p}=g \times 6.89 \times 10^{-2} \beta^{-0.5} \xi^{-1.376} U_{10}^{-1}$

The computation of $E_{\text {w }}$ needs the $f_{\text {min }}$ value. An iterative method similar to Golding (1983) is employed:

i) Compute $E_{w_{\text {max }}}$ from (12) taking $E_{w}=E_{w_{\text {max }}}$ as the first guess;

ii) Compute $\xi \alpha$ and $f$, from $\mathrm{Eq}(11)$ and $\mathrm{Eq}(13)$ :

iii) Compute $f_{\text {min }}$ from

$$
\bar{E}_{w}=\int_{l=-}^{x} E_{w}^{0} d f=\begin{aligned}
& \alpha g^{2} \quad 1 \\
& (2 \pi)^{4} 4 f_{p}^{4}
\end{aligned}(3-2 \mu), \mu=f_{\text {min }}, .
$$

iv) Compute $E_{w}$ in the domain $\theta_{w}-\pi / 2<0<0_{w}+$ $\pi / 2, f_{\text {initi }}<f$ :

(v) Return to ii) and repeat the process (a stable value is reached after $2-3$ iterations)

\section{Wind-sea angular spreading}

The parameterization of the angular spreading of the frequency spectrum is given by (Guillaume, 1990):

$E_{s p r}=G(\theta) \bar{E}_{w}^{0}$, for $\theta_{w}-\pi / 2<\theta<\theta_{w}+\pi / 2$

With

$G(\theta)=\left\{\begin{array}{ccc}\pi^{2} \cos ^{2}\left(\theta-\theta_{w}\right) & \text { for } & \theta-\theta_{w}<\pi / 2 \\ 0 & \text { otherwise }\end{array}\right.$

In the case of a rapid wind shift, this procedure may not be correct, since an instantancous angular relaxation with maximum energy along the direction $\theta_{w}$ is produced. A better procedure would be a relaxation where the energy migrates gradually into this direction, as simulated by 3 rd generation models. Janssen et al. (1984) tunes the $G$ function on a mean direction. They compute the direction though with both swcll and wind-sea cnergies. SG presents a new alternative scheme. In this scheme part of the energy is retained in each direction by the angular spreading. It is defined

$E_{\text {them }}(\theta)$ : Energy in a $\theta$ direction before the angular spreading computation;

$E_{y^{\prime \prime}}^{\prime}(\theta)$ : Energy spreading formula given by Eq.(15) and integrated for $f>f_{\min }$;

$E_{m}^{\prime}(O)$ : Energy to be retained in the $\theta$ direction.

It is suggested here to find $E_{\text {n'w }}$ satisfying the following basic properties:

$$
\begin{aligned}
& \frac{f}{E_{n e w}}=\frac{E_{r e t}}{f}+\frac{E_{s p r}}{f} ; \\
& \bar{E}_{r e t}^{f} \text { is proportional to }\left|\sin \left(\theta-\theta_{w}\right)\right| ;
\end{aligned}
$$

$E_{r c t}^{f}$ is proportional to the difference
$E_{r e t}^{f}-E_{s p r} ;$ 
If $\bar{E}_{s p r}^{f}>\bar{E}_{\text {before }}^{f}$ no energy is retained;

If $\bar{E}_{s p r}^{f}<\bar{E}_{\text {before }}^{f}$ then $\bar{E}_{\text {new }}^{f}<\bar{E}_{\text {before }}^{f}$.

An angular spreading satisfying these requirements is given by

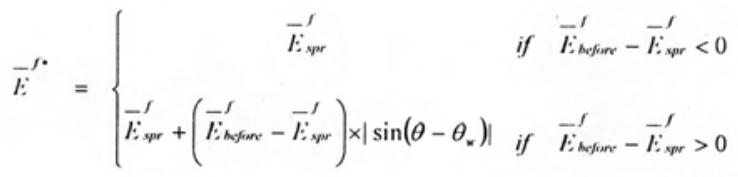

In order to conserve the wind-sea energy

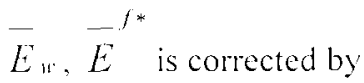

$$
\begin{gathered}
\bar{E}_{n e w}^{f}=\frac{\bar{E}^{f *} \times \bar{E}_{w}, \text { and finally }}{\bar{E}^{\cdot}} \\
\bar{E}_{n e w}=\frac{\bar{E}_{w}^{0} \times \bar{E}_{n{ }^{\prime} w}^{f}}{\bar{E}_{w}}
\end{gathered}
$$

The instantaneous nonlinear energy adjustment over the frequency range to the spectral shape prescribed makes also a rapid migration of energy toward the peak frequency. This can be avoided applying a gradual migration of encrgy similar to that suggested here for angular relaxation. The choice of a more suitable scheme to perform both directional and frequency a gradual transfer in terms of direction and frequency should be guided by observations and a 3 rd generation model.

\section{Input and dissipation of energy} Miles (1960)

The wind input follows Phillips (1957) and

$$
S_{i n}=\gamma+\beta E,
$$

where

$$
\gamma=\left\{\begin{array}{cc}
6 \times 10^{8} U_{10}^{2} \cos \left(\theta-\theta_{w}\right) & \text { for } f=f_{\max } \text { and } \theta-\theta_{u}<\pi \\
2 \pi f_{\max } & \text { otherwise }
\end{array}\right.
$$

and
$\beta=\left\{\begin{array}{cc}C f\left(\begin{array}{cc}U \cos \left(\theta-\theta_{w}\right) \\ c\end{array}\right. & \text { if } U \cos \left(\theta-\theta_{w}\right)>{ }_{2} \\ 0 & \text { otherwise }\end{array}\right.$

Where $c$ is the phase velocity.

The dissipation due to wave breaking or white-capping follows Golding (1983),

$S_{d s}=-D f^{2} E(f, \theta) \times \bar{E}^{0.25}$.

The parameters $C$ and $D$ are adjusted so that the duration-limited growth resembles the cmpirical relation given by Sanders (1976). In his results the significant wave height is given by

$H_{s}={ }_{g}^{U_{10}^{2}} \tanh \left[6.1 \times 10^{-4}\left(\begin{array}{c}g t \\ U_{10}\end{array}\right)^{0.75}\right]$.

The energy dissipation due to the bottom firiction follows Hasselmann et al. (1973). No dissipation due to opposing winds and swell attenuation are included at the present moment. Arguments in favour of this approach have been obtained in laboratory experiments conducted by Young \& Sobey (1985).

\section{Idealised experiments}

Numerical experiments under hypothetical and idealised conditions were carried out, in order to identify the main characteristics of $\mathrm{SG}$. First the parameters $C$ and $D$, in the parameterisation of the atmospheric input of energy and dissipation, were tuned in order to reproduce the empirical Eq. (20). Then a few experiments as described by $\$ 85$ were performed. The basic differences and similarities among SG and other models are discussed in Imnocentini \& Cactano (1996). Here only the duration-limited growth experiment is presented.

\section{Duration-limited growth}

In this experiment only one spatial point is considered. The wind is maintained at a constant value, and waves evolve due to $S_{i m}, S_{i s}$ and $S_{m}$. The ocean depth is set to a constant value of $500 \mathrm{~m}$. This case reproduces an infinite and deep ocean where the waves are forced by a constant and uniform wind The purpose is to tune parameters of the source-terms representing the three physical processes to the duration-limited growth curve given by Sanders (1976). Figure 2 presents the SG results obtained with:

$C^{\prime}=2 \pi \times 12 \times 10^{-5}$ 
a)

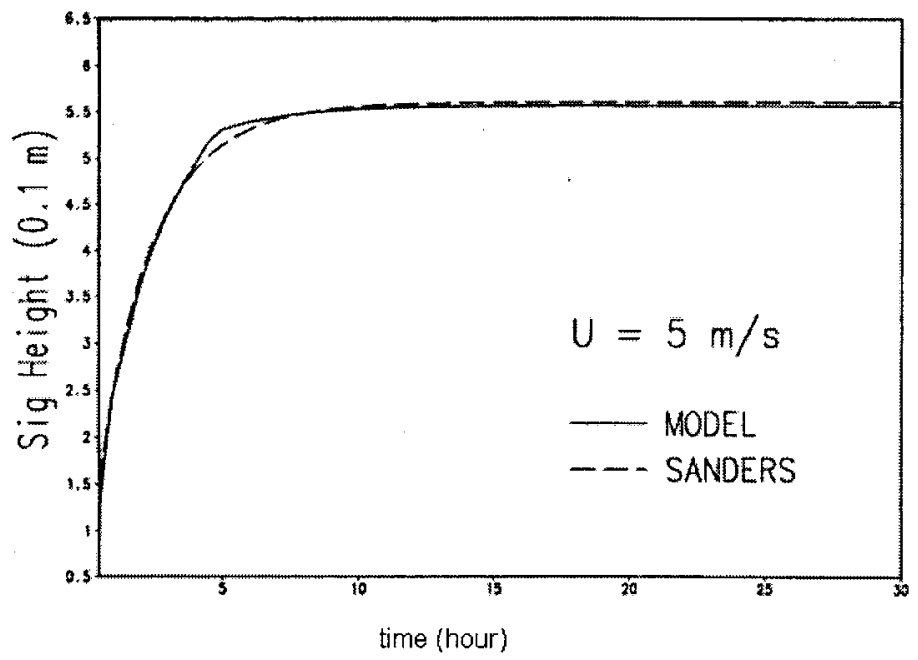

b)

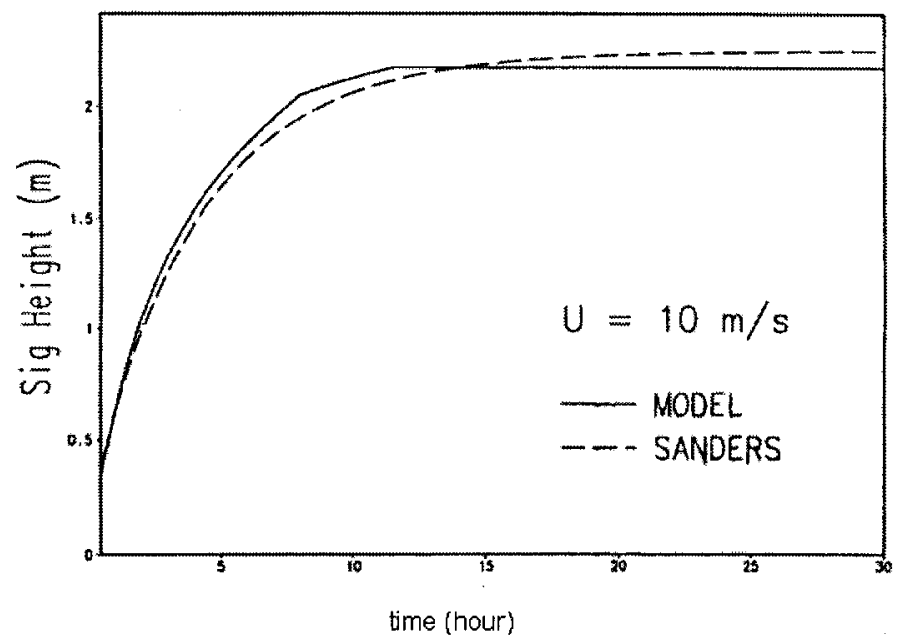

c)

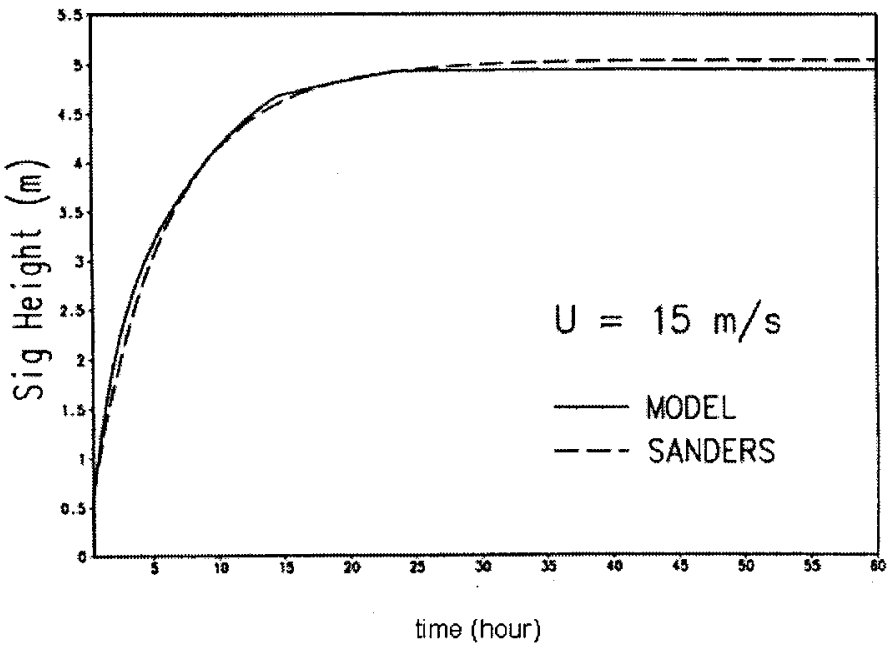

Fig. 2. Duration-limited growth curves representing the significant wave height as a function of time. Full lines are Eq. (20), whereas broken lines is the numerical model result for $\mathrm{U}_{10}$ equal to (a) $5 \mathrm{~ms}^{-1}$, (b) $10 \mathrm{~ms}^{-1}$, (c) $15 \mathrm{~ms}^{-1}$, (d) $20 \mathrm{~ms}^{-1}$, (e) $25 \mathrm{~ms}^{-1}$ and (f) $30 \mathrm{~ms}^{-1}$. 
d)

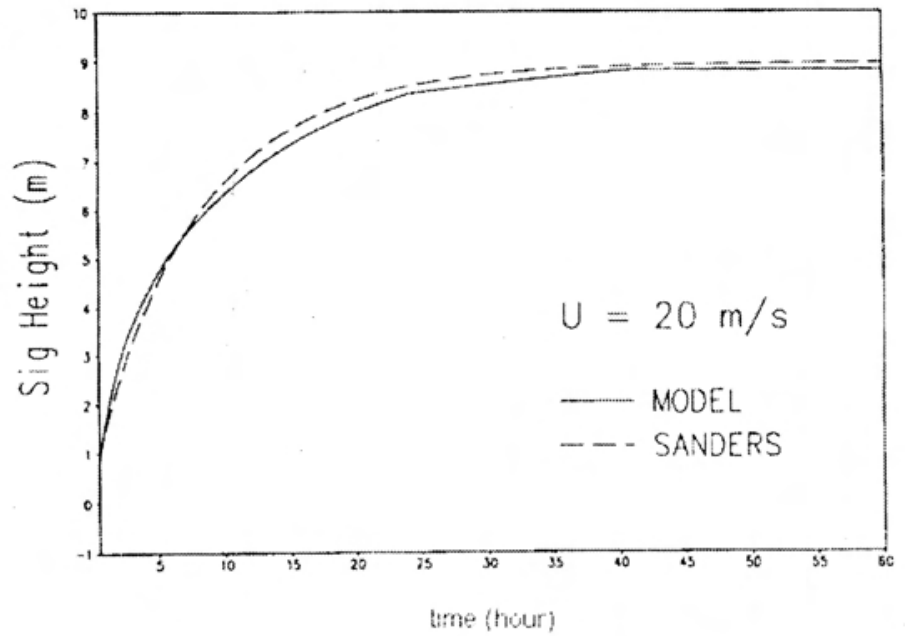

c)

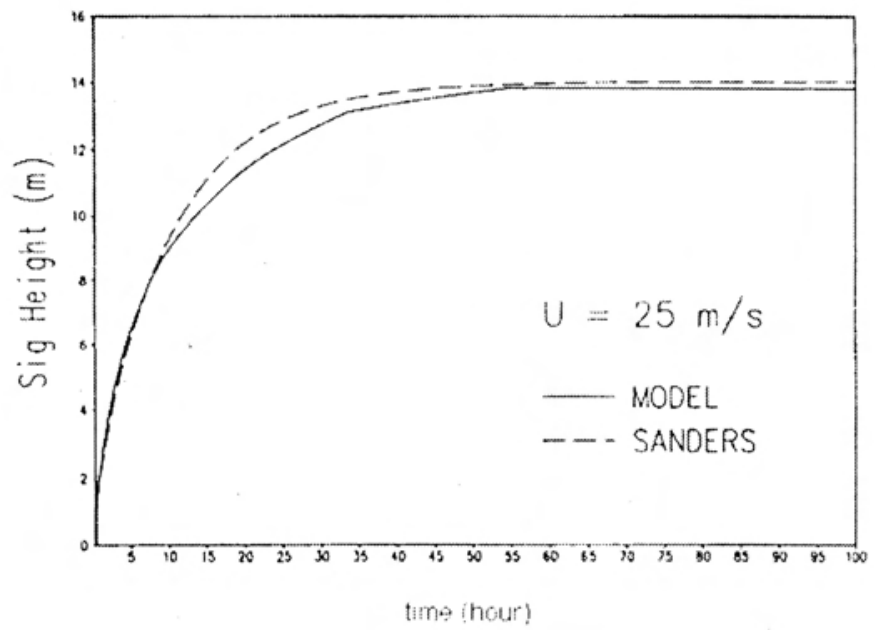

f)

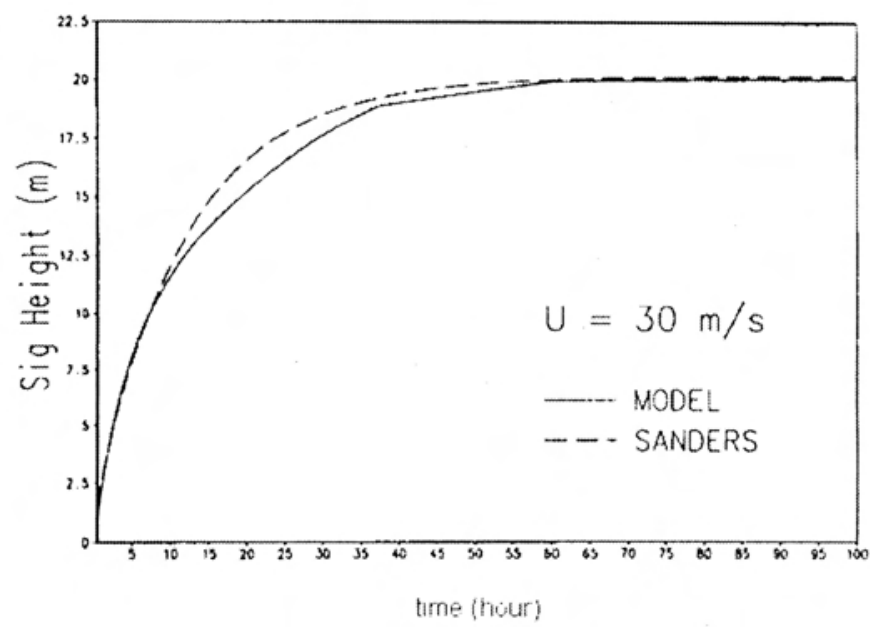

Fig. 2. Cont. 


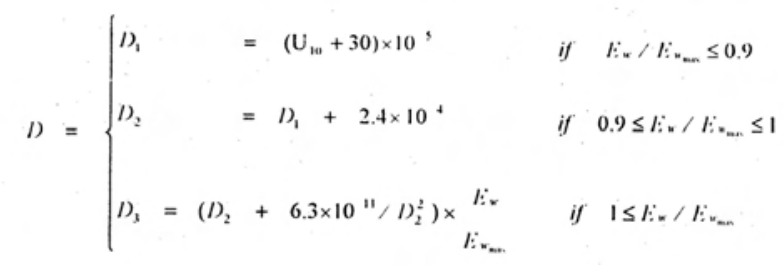

and Eq. (20) for the velocities 5, 10, 15, 20, 25 and 30 $\mathrm{ms}^{-1}$. The model reproduces the empirical curve reasonably well for all velocities and rarely the error is greater than $5 \%$. The error is about $7 \%$ around the time-step 50 for the $U=25 \mathrm{~ms}^{-1}$ experiment.

The time spectral evolution can be analysed from (Fig. 3), where the frequency spectrum for $U_{10}=$ $20 \mathrm{~ms}^{-1}$ is ploted for the fully developed spectrum and for the hours 9. 18, 27, 36 and 90. Qualitatively the spectrum increases with the time while the peak frequency decreases due to the nonlinear interactions. After $1=40$ h the contributions of 3 source terms are in balance. ceasing the spectral growth. The overshoot phenomenon is observed at $\mathrm{t}=9 \mathrm{~h}$ and $\mathrm{t}$. $18 \mathrm{~h}$ on higher frequencies side of the fully developed spectrum peak frequency. Excess energy for the fully developed spectrum has been also noted in data analysed by Barnet \& Wilkerson (1967) and Hasselmann el al. (1973). After $t=90$ h a stcady state is achieved fitting the fully developed spectrum on the higher frequency side, but slightly smaller on the other lover frequencies side.

\section{Mediterrancan sea events}

In order to illustrate the performance of $\mathrm{SG}$ in real events were performed a hindcast for the Mediterancan Sea with December 1992 wind fields data provided by the ECMWF. The high incidence of active mcteorological events in this region, as pointed out by Dellosso $4 \mathrm{al}$ (1992), and the large quantity of available observations ( 8 stations) enhance the possibilities of comparison and evaluation among the two models and data in different configurations of strong winds.

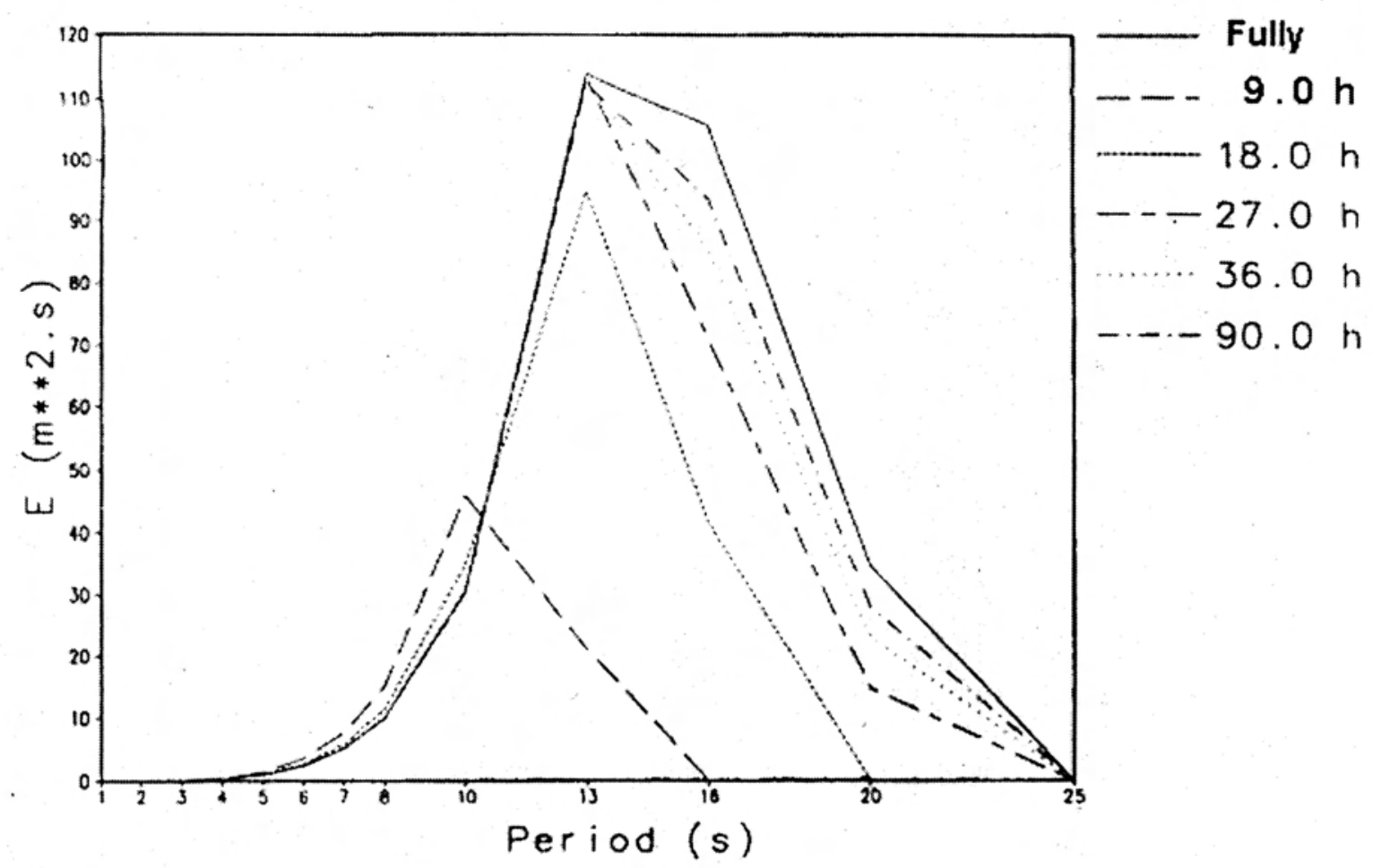

Fig. 3. Time evolution of the spectrum for duration-limited growth curve calibration with $U_{10}=20 \mathrm{~ms}^{-1}$. 


\section{December 1992 episodes}

The wave data collected from the buoy network deployed by the Italian Ministry of Public Works depicted in Figure 4 . The buoy station distribution allows the comparison of wave data and model results in several storm configurations. Depending on the wave direction, a buoy can show wave behaviour not affecting another buoy due to some natural barrier. For example, a storm in the Ionian Sea (off the south coast of Italy) with northwestward wind produces waves detected in $\mathrm{CR}$ $(39 \mathrm{~N}, 17.5 \mathrm{E})$ and $\mathrm{CA}(37.5 \mathrm{~N}, 15.5 \mathrm{E})$ buoys, while easterly winds on the Tyrrhenian Sea (off the western coast of Italy) generates waves which can be measured in PO $(41 \mathrm{~N}, 13 \mathrm{E})$. Fetch in both cases is obstructed by the presence of Sicily and Italic peninsula.

An examination on the time series of the significant wave height $\left(H_{S}\right)$ obtained by the buoys can identify the main active meteorological events during the study period. Table 1 presents the date with $H_{S}$ greater than $3.5 \mathrm{~m}$ for the 8 stations. A brief description of the wind characteristics as shown by ECMWF gridded analysis in each episode and the accompanying wave condition reported by the buoy network is given below.

\section{The 6 December event}

This event affected mainly the Algerian and Tyrrhenian Basins. It was first detected at LA 2 days earlier. The winds presented a cyclonic curvature and a jet streak displacing downstream from south of France to Ionian Sea. Figure $5 \mathrm{a}$ presents the $10-\mathrm{m}$ wind field at $00 \mathrm{Z}$ and $06 \mathrm{Z} 6$ December 1992. The wind reached $21 \mathrm{~ms}^{-1}$ at $06 \mathrm{Z} 6$ December on the Tyrrhenian Sea (Fig. 5b). The maximum wind at $\mathrm{AL}$ $(40.5 \mathrm{~N}, 8 \mathrm{E})$ buoy (taken from the nearest grid point to the buoy location) was $18 \mathrm{~ms}^{-1}$. The highest wave heights reported at the buoys affected by this event were $4.0 \mathrm{~m}$ at $\mathrm{AL}, 3.9 \mathrm{~m}$ at $\mathrm{MA}(37.5 \mathrm{~N}, 12.5 \mathrm{E}), 5.7 \mathrm{~m}$ at $\mathrm{PO}$, and $4.8 \mathrm{~m}$ at $\mathrm{LA}(44 \mathrm{~N}, 9.5 \mathrm{E})$. However missing data around 00Z 6 December are observed at AL, MA and PO, and perhaps higher waves might be achieved by that time on these buoys, specially AL. The southwesterly winds on the Ionian Sea were short lived and unable to affect $\mathrm{MO}(42.5 \mathrm{~N}, 17.5 \mathrm{E})$ at the entrance of the Adriatic Sea.

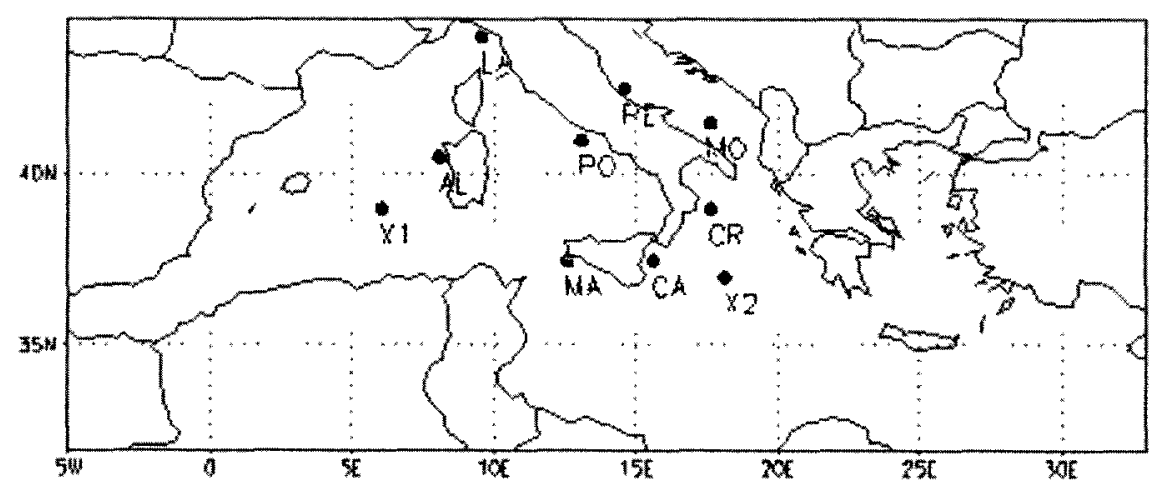

Fig. 4. Spatial domain used by the numerical models and the buoy network with, $\mathrm{AL}=\mathrm{Alghero}(40.5 \mathrm{~N}, 8 \mathrm{E}), \mathrm{CA}=\mathrm{Catania}(37.5 \mathrm{~N}, 15.5 \mathrm{E}), \mathrm{CR}=$ Crotone $(39 \mathrm{~N}, 17.5 \mathrm{E})$, $\mathrm{MA}=$ Mazara del Vallo $(37.5 \mathrm{~N}, 12.5 \mathrm{E}), \mathrm{MO}=$ Monopoli $(41.5 \mathrm{~N}, 17.5 \mathrm{E})$, $\mathrm{PE}=$ Pescara $(42.5 \mathrm{~N}, 14.5 \mathrm{E}), \mathrm{PO}=$ Ponza $(4 \mathrm{IN}, 13 \mathrm{E}), \mathrm{LA}=$ La Sperzi $(44 \mathrm{~N}, 9.5 \mathrm{E}) \mathrm{X} 1$ and $\mathrm{X} 2$ indicate two points discussed in this study.

Table 1: Date with significant wave height (SWH) greater than $3.5 \mathrm{~m}$ during December 1992.

\begin{tabular}{|l|c|c|c|c|}
\hline Station & Alghero (AL) & Catania (CA) & Crotone (CR) & La Sperzi (LA) \\
\hline Date & $\mathbf{6} ; 8 ; 13$ & $19 ; 26$ & $18 ; 26 ; 29$ & 4 \\
\hline \hline Station & Mazara del Valle (MA) & Monopoli (MO) & Pescara (PE) & Ponza (PO) \\
\hline Date & 6 & 29 & 28 & 6 \\
\hline
\end{tabular}


a)

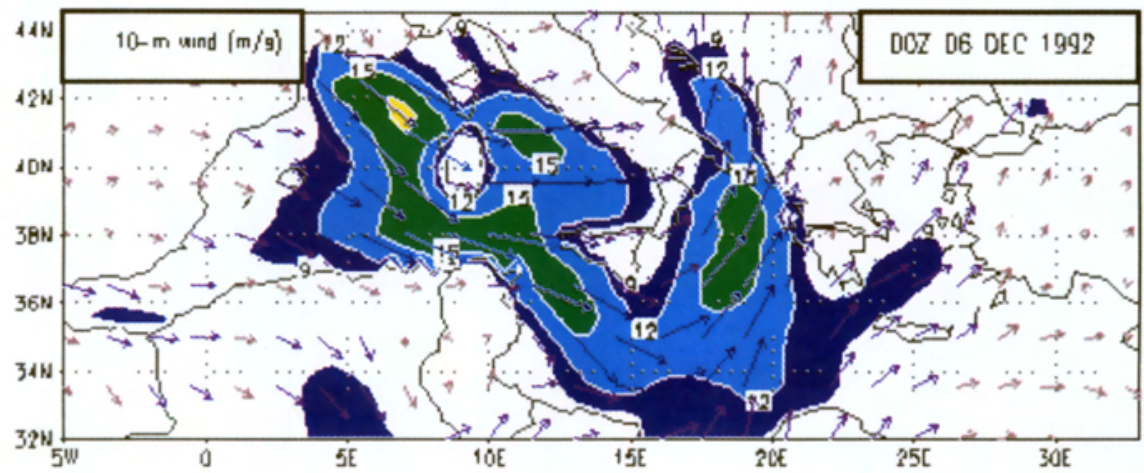

b)

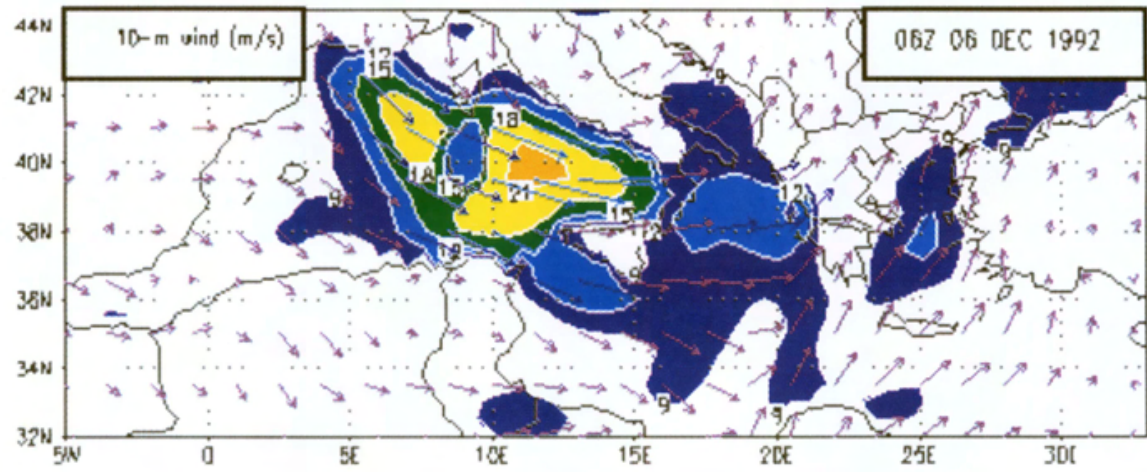

c)

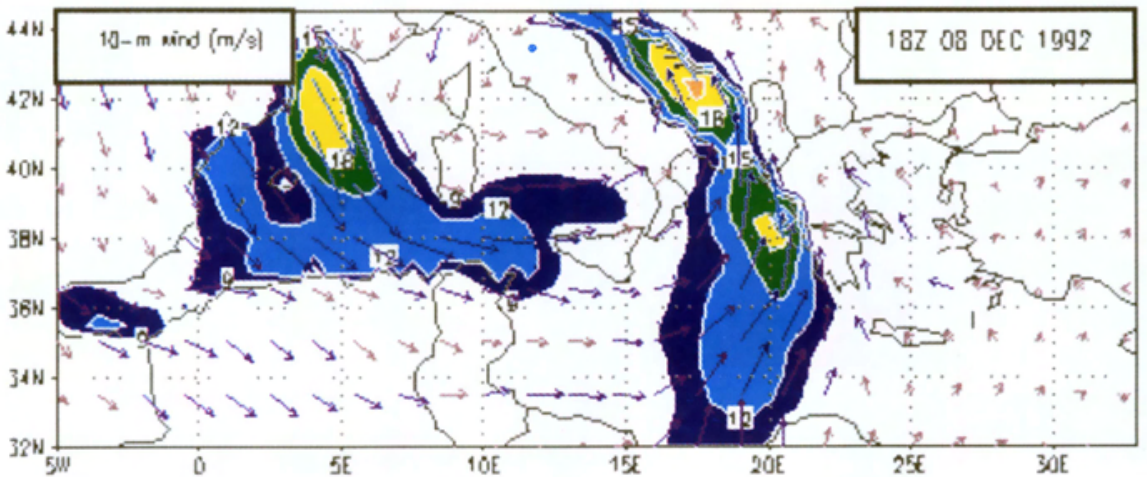

Fig. 5. $10 \mathrm{~m}$ wind field provided by ECMWF at (a) 00Z 6 December 92; (b) $06 \mathrm{Z} 6$ December 92; (c) $18 Z 8$ December 1992; (d) $12 Z 13$ December 1992; (e) 12 Z 18 December 1992. Shading area denotes isotachs higher than $9 \mathrm{~ms}^{-1}$. The contour interval is $3 \mathrm{~ms}^{-1}$. 
d)

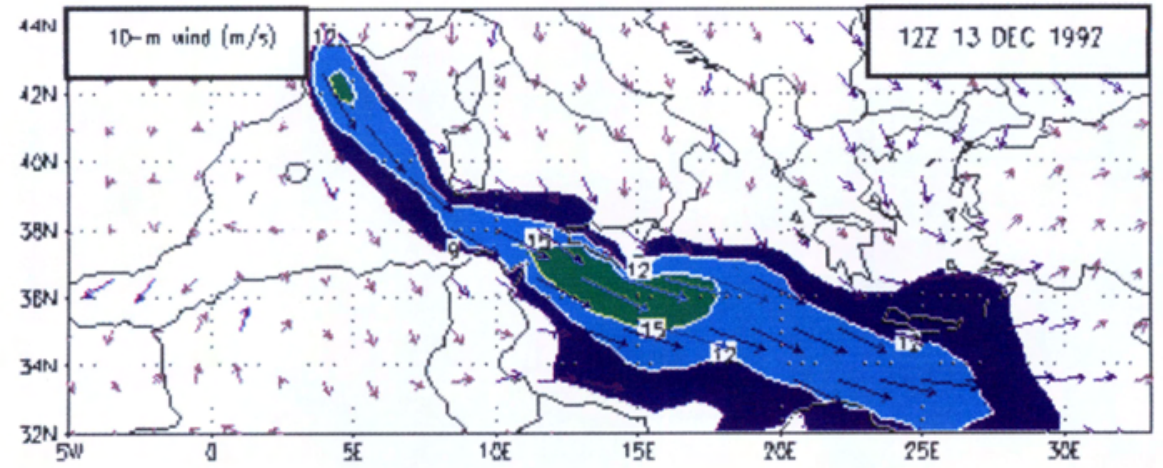

e)

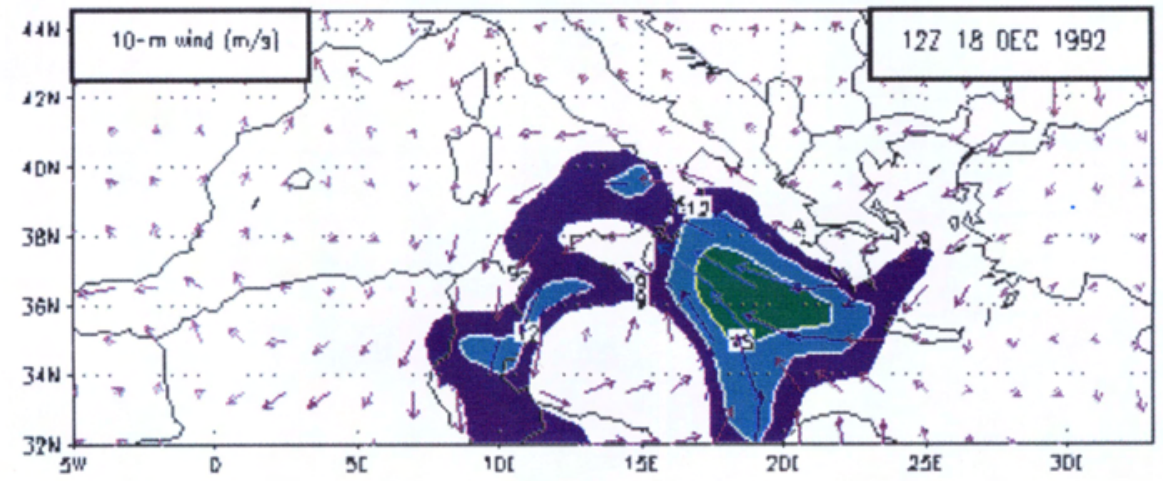

Fig. 5. Cont.

\section{The 8 December event}

This episode seems to be a restart of the previous event, after a brief pause. The curvature of the wind on the Ionian Sea increased and the jet streak propagates northeastward reaching the Adriatic Sea. Strong wind speeds developed over Algerian and Tyrrhenian Basins like the 6 December event, but slightly displaced towards Africa. Figure $5 \mathrm{c}$ shows the wind field at $18 \mathrm{Z} 8$ December. The highest wave heights reported were $4.1 \mathrm{~m}$ at $\mathrm{AL}, 3.0 \mathrm{~m}$ at MA, and $3.0 \mathrm{~m}$ at $\mathrm{PE}(42.5 \mathrm{~N}, 14.5 \mathrm{E})$. Although nearest grid points to $C R$ and MO presented wind $12 \mathrm{~ms}^{-1}$ and 18 $\mathrm{ms}^{-1}$, the wave height reported at these buoys were less than $2.5 \mathrm{~m}$. This discrepancy will be discussed in the next section.

\section{The 13 December event}

Like the previous episodes, a jet streak moved downstream from south of France. However, the cyclonic curvature is smaller, and the core of strong winds did not propagated into the Ionian and Adriatic Seas. The wind field at $12 Z 13$ December is shown in Figure 5d. A fetch is well defined along the Mediterranean Sea and Levantine Basin. The wind near AL reached $12 \mathrm{~ms}^{-1}$, and the buoy reported $5.0 \mathrm{~m}$ wave height. MA reported less than $3.2 \mathrm{~m}$, although the wind was $15 \mathrm{~ms}^{-1}$.

\section{The 18 December event}

This event is restricted to south of the Ionian Sea. It started at $18 \mathrm{Z} 17$ December with a closed cyclonic curvature imposing a fetch towards $\mathrm{CA}$ and CR buoys. In the next 24-hour period a core with wind speed larger than $15 \mathrm{~ms}^{-1}$ developed, as presented in Figure 5e at $12 \mathrm{Z} 18$ December. At the nearest grid point to the buoys $C A$ and $C R$, wind speeds greater than $12 \mathrm{~ms}^{-1}$ were detected. Both buoys waves heights greater than $4 \mathrm{~m}$.

\section{The 26 December event}

This event was constituted by easterly winds resembling a wavelike pattern with alternating cyclonic and anticyclonic curvatures. As shown in Figure 6a at 18Z 26 December, a jet streak was generating waves affecting south of Italy. Another jet streak, less intense, was detected on the northwest Algerian Basin. During the next 18 hours the later jet streak decreased while the former moved westward and changed its cyclonic curvature to anticyclonic as shown in Figure 6b. The gridded 10-m winds near CA and CR were $16 \mathrm{~ms}^{-1}$ and $12 \mathrm{~ms}^{-1}$, and the reported wave height were $5.1 \mathrm{~m}$ and $3.7 \mathrm{~m}$, respectively. 


\section{The 28 December event}

While the 26 December episode was weakening, a core constituted by northeasterly winds with $15 \mathrm{~ms}^{-1}$ on the Adriatic Sea was observed, as shown in Figure 6c at $06 Z 28$ December. The next 12-hour period was characterised by a closed cyclonic curvature on the Ionian Sea, and another larger on the
Algerian and Tyrrhenian Basins (Fig. 6d at $18 Z 28$ December). A tendency of increasing wave heights was noted in all buoys, except in MA. The highest wave and corresponding wind speed were $4.5 \mathrm{~m}$ and $17.5 \mathrm{~ms}^{-1}$ in CR, $3.9 \mathrm{~m}$ and $13 \mathrm{~ms}^{-1}$ in $\mathrm{MO}, 4.4 \mathrm{~m}$ and $15 \mathrm{~ms}^{-1}$ in PE.

a)

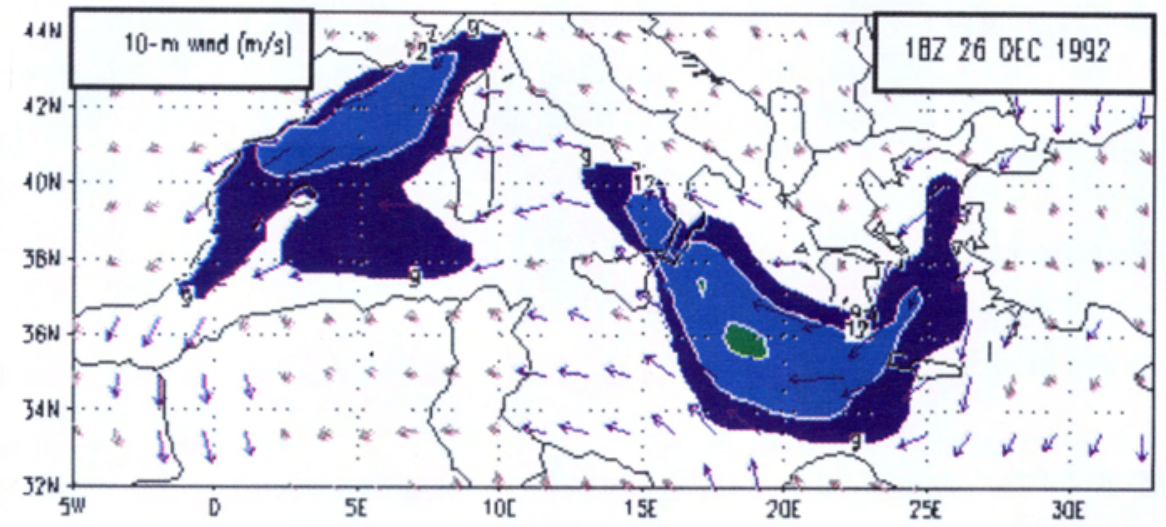

b)

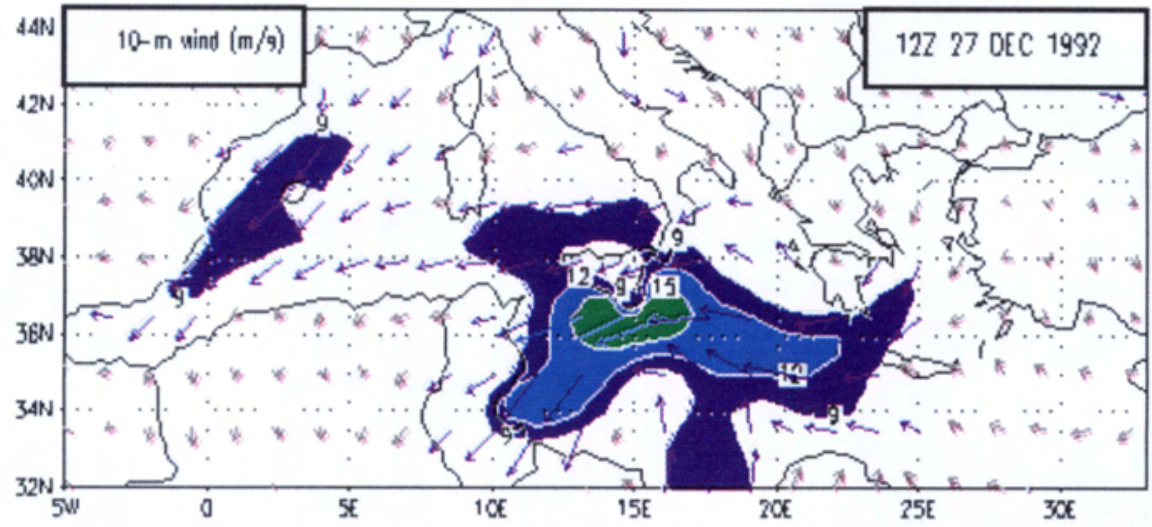

c)

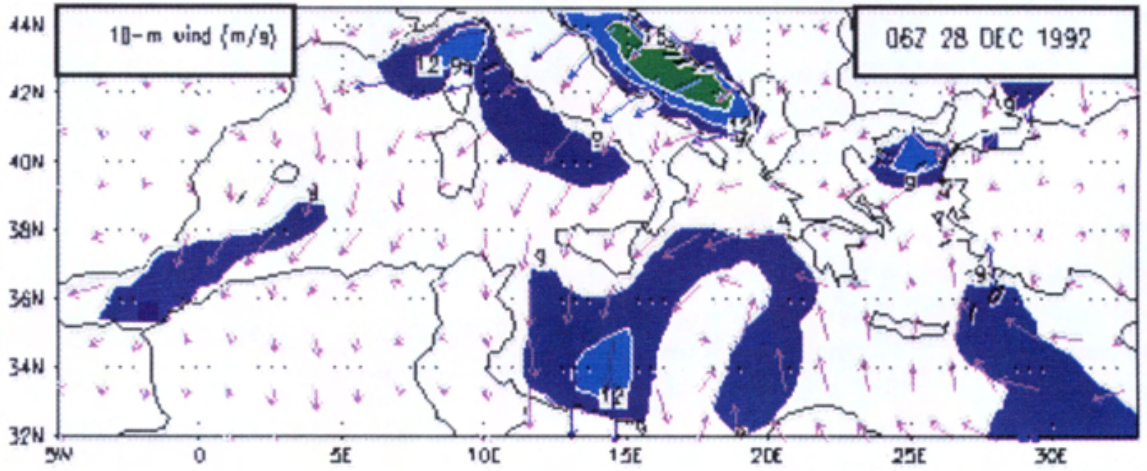


Fig. 6. As in Figure 5, but at (a) 18Z 26 December 1992; (b) $12 Z 27$ December 1992; (c) 06Z 28 December 1992 and (d) 18Z 28 December 1992.

d)

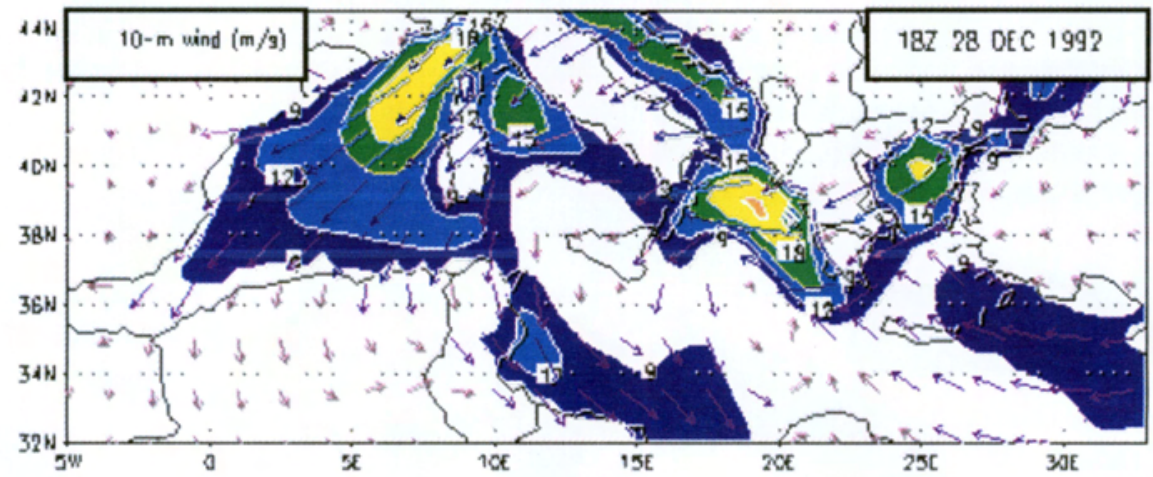

Fig. 6. Cont.

\section{Evaluation of the wave hindcast}

The 10-m winds were provided by ECMWF initialised analysis at 6-hour interval. The spectral truncation was T213 corresponding to $0.5^{\circ}$ grid resolution in a geographic grid mesh.

Both wave models were integrated from $00 Z$ 01 December to $18 Z 31$ December 92. The input winds are provided at 6-hour interval, and the output at 3-hour interval for comparison against the 3-hour available buoys observations. The model is initialized with a flat sea and the ECMWF wind and bathymetry fields are interpolated to the grid mesh used in the wave models. The model output at the grid point nearest to the buoy location is compared to the buoy measurements. The buoy products available are $H_{S}$, mean wave period, and mean wave direction at each 3-hour period for December 92.

It has been recognised that error in wind are the primary source of deficient wave modelled results. Also, in the evaluation of numerical results, it is very difficult to isolate errors provided by the wave model from those by the wind fields (Gunther \& Rosenthal, 1995).

Inadequate resolution of the wind field is another source of discrepancy. The impact of spatial and temporal resolution of the wind forcing the WAM was studied by Graber et al. (1995). They concluded that wind supplied by operational centres generally has poorer performance for mesoescale meteorological events and a re-analysis with finer resolution during mesoescale storm events is necessary. However, when the evolution of the meteorological event is slow, a horizontal resolution of $1.5^{\circ}$ spacing and 6-hour sampling appears to be satisfactory in the WAM simulations. On the other hand, in areas of atmospheric fronts and rapidly propagating jet streaks, $0.5^{\circ}$ spacing and no more than 3-hour interval for the wind field are required to obtain satisfactory results. Unfortunately wind measurements were not available in this study, which make difficult to assess the quality of the wind field. Also the wind forcing the wave models has a 6-hour temporal resolution.

\section{Comparison between the wave models at a well offshore point}

Since the 8 buoys are located very near the shore and consequently the wave data affected by shallow water effects, the behaviour of the two models are compared at an offshore grid point. The locations X1 and X2 (see Fig. 4) were defined for this objective. An examination on $\mathrm{X} 1$ and $\mathrm{X} 2$ time series revealed similar properties, so only the results on point X1 will be presented here (Fig. 7).

Both models show similar $H_{S}$ results during the wave growth stage. SG model tends to delay the beginning of the decay stage and simulates wave peaks slightly greater. The mean wave period of the SG is smaller, and the WAM presents smoother variation. The only exception, with the WAM exhibiting higher $H_{S}$, was 13 December. A close examination at this date revealed that the mean wave period of WAM was considerably greater, although the wind speed was decreasing. This suggests that a swell reaching this point was simulated by WAM.

When the $H_{S}$ is higher than $2 \mathrm{~m}$, the difference of mean wave direction between the models were smaller than $20^{\circ}$. Substantially larger differences occurred when the wave heights were less than $1 \mathrm{~m}$.

\section{Comparison between model results and buoy measurements}

During the period-analysed two remarkable opposite wind regimes in the Mediterranean Sea were evidenced by the ECMWF 10-m winds. Before 13 December the low pressure centres were located above Northern Mediterranean, and the winds present 

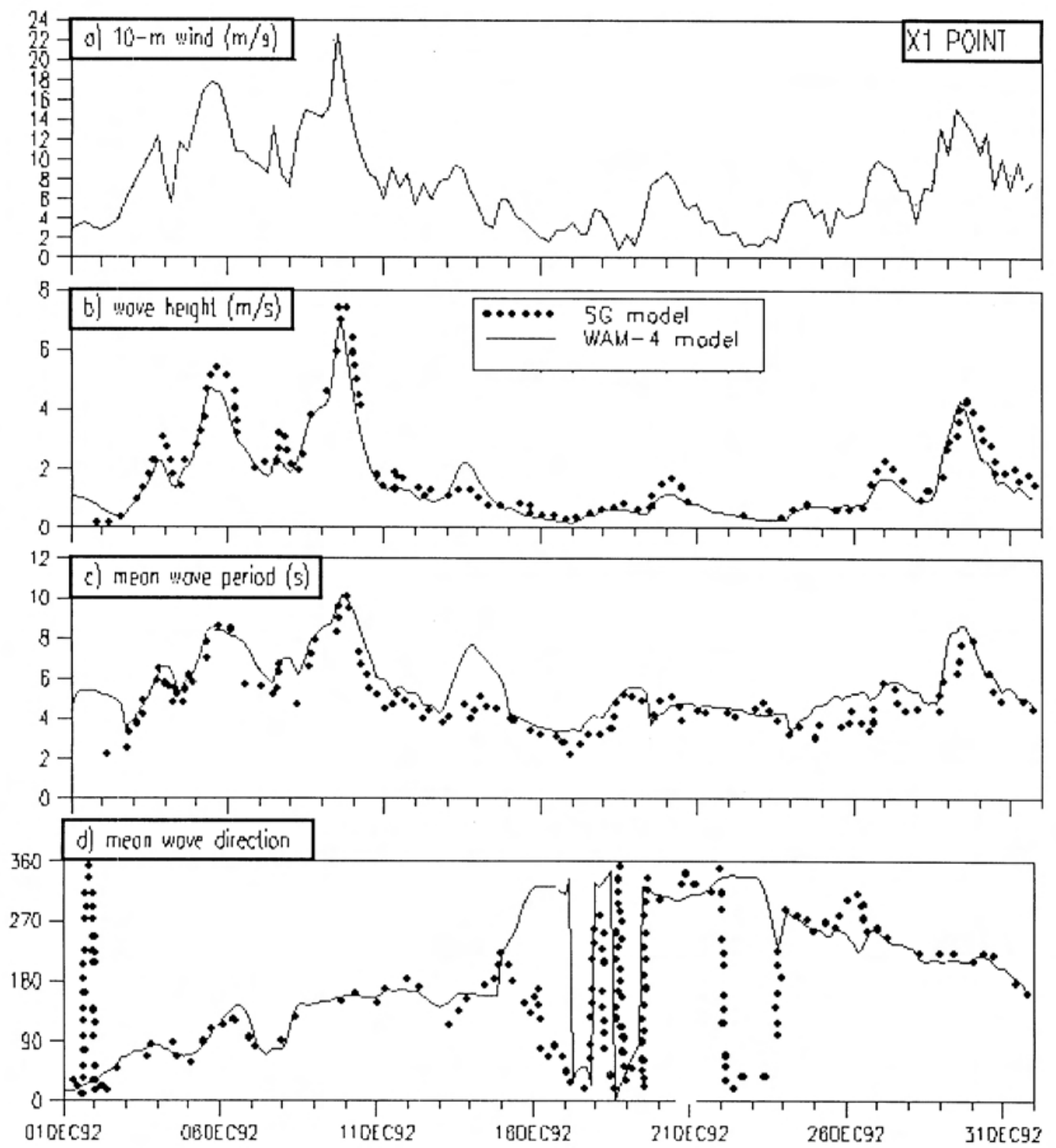

liig. 7. Time series of simulated SWII by SC $\mathrm{i}$ and WAM models at location XI.

In addition to the particular characteristic of each model pointed above, one must keep in mind two kinds of shortcoming related to the performance of both numerical models when comparing their results with measurements. Gunther \& Rosenthal (1995) emphasised the excellent performance of the WAM at decp occan and shallow water shelf areas, and difficulties in the coastal zone. Another difficulty is with wind error (or inadequate resolution): some buoys reported $H_{5}$ values not compatible with the wind provided and contrasting with both modelled results.

\section{Adriatic Sea buoys}

Before 13 December the wind fields on this region were south-southeasterly and northnortheasterly after 26 December. The growth and decay stages of the two models agree well with the buoys PE and PO, but the measurements of PE are higher during all period. Figure 8 presents the MO time series. The tendency noted in PE is repeated at $\mathrm{MO}$ on the sccond wind regime. The SG wave model presented better performance than the WAM during the 28 December storm. Many data in the beginning of December are missing and the discussion becomes cumbersome. 

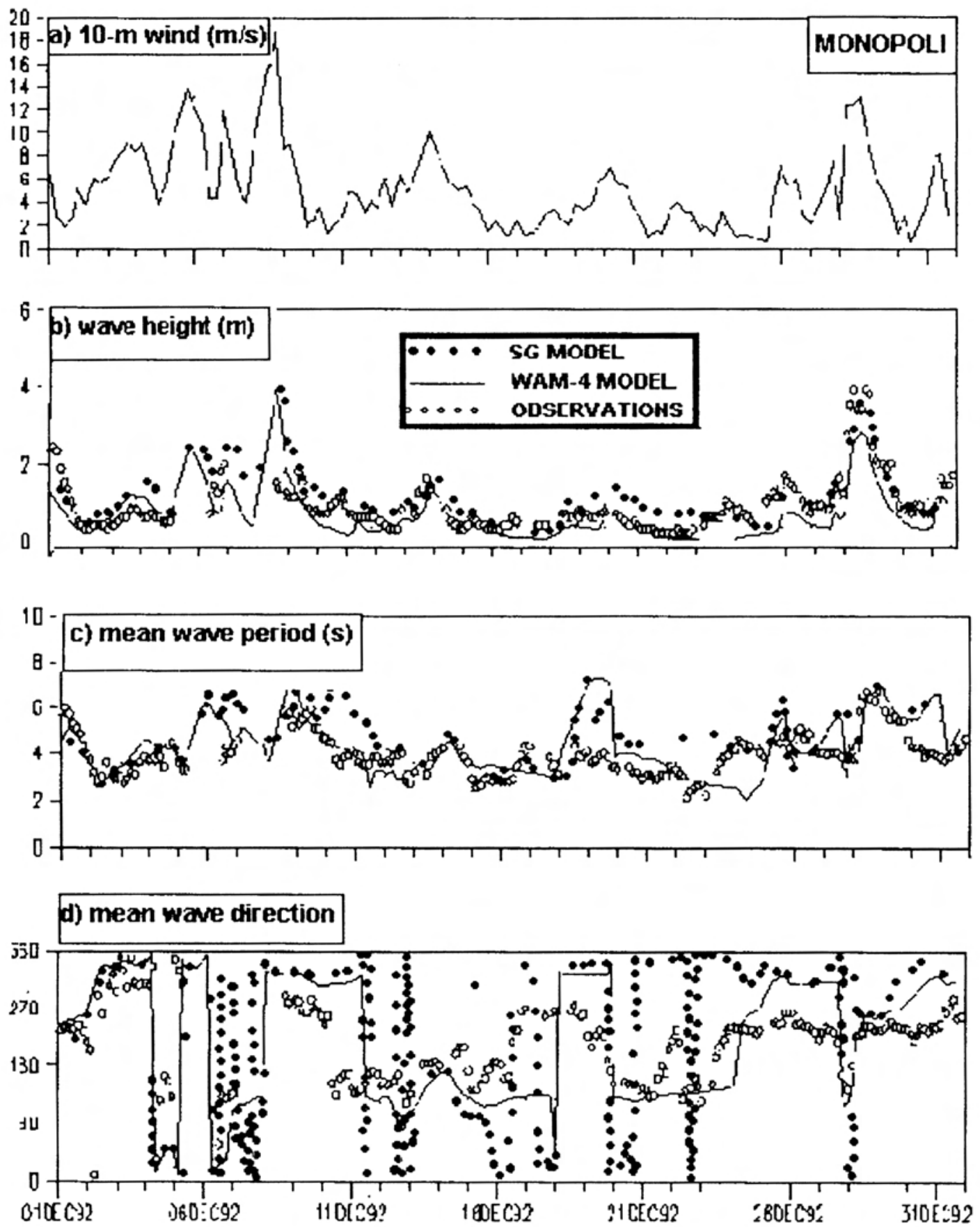

Fig. 8. Monopoli time series of (a) observed wind. (b) observed and simulated SWII. (c) observed and simulated period. and (d) observed and simulated direction.

Ionian Sea buoys

The CA and CR buoys are located in this region. Both models simulated $\mathrm{SWH}$ higher than the observed, and a general tendency of SG to delay the decay stage causing greater errors than the SWII simulated by the WAM. The CR time series is presented at rigure 9. The general features of both models make the SG better at 18 December storm.
Both models were unable to follow the wave growth nearly before 25 December. Since the winds were below $8 \mathrm{~ms}^{-1}$ and the period observed less than $6 \mathrm{~s}$, there is some evidence that the wind field error was responsible for this discrepancy. The 28 December wind reported almost $18 \mathrm{~ms}^{-1}$ and the $\mathrm{SG}$ responded very quickly generating a $H_{s}$ of $7 \mathrm{~m}$, greater than the maximum $4.8 \mathrm{~m}$ observed at the buoy $\mathrm{CR}$ for this storm. 

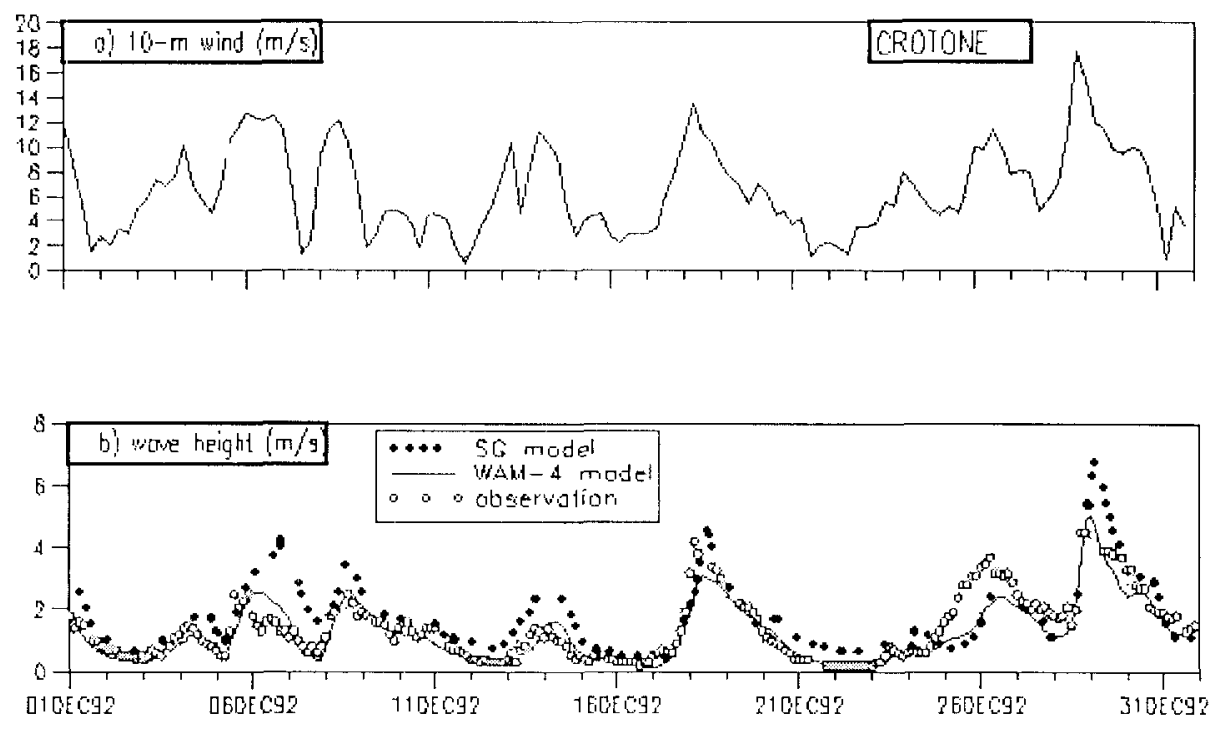

Fig. 9. As lig. 8 but Crotone.

\section{Tyrrhenian Sea}

The PO buoy is located at this basin. The MA buoy is in shallow water and in the entrance of it. Both buoys presented few instances of $/ I_{\mathrm{s}}$ higher than $3 \mathrm{~m}$ during the first wind regime period. Figure 10 presents the $H_{S}$ measured at PO. It is interesting to note that both models underpredicted the $I_{\text {s }}$ observed in mostly all second wind regime.

\section{Algerian Basin}

The two buoys in this basin are $\mathrm{AL}$. and L.A. Boh buoys reported waves higher than $2 \mathrm{~m}$ just in the first wind regime. Figure 11 shows the $\mathrm{Al}$. time series. Note around 8 December a $4 \mathrm{~m}$ wave height observed, was not simulated by both models. $\wedge$ close examination on the winds shows that they were below $10 \mathrm{~m}$, and it seems that the ECMWF wind field presents a large error. At 13 December both models show a delay in the growth stage and at 28 December they respond to an increasing wind, which was not observed. In the Table 2 is presented the root-mean-square difference (rmsd) between both models simulations and bouys $H_{s}$. One can see the difference between two $H_{x}$ are the same order the magnitude for both models. On the other hand the temporally varying of the rmsd for the MO station shows maximum difference value of $2.5 \mathrm{~m}$ on December 8,1992 for both simulations (Fig. 12). Since the direction of this wind is north-northeasterly, a close examination on the shoreline near this bury shows that perluaps the land obstruction was not captured by the wave models. Probably the spatial resolution should be greater.
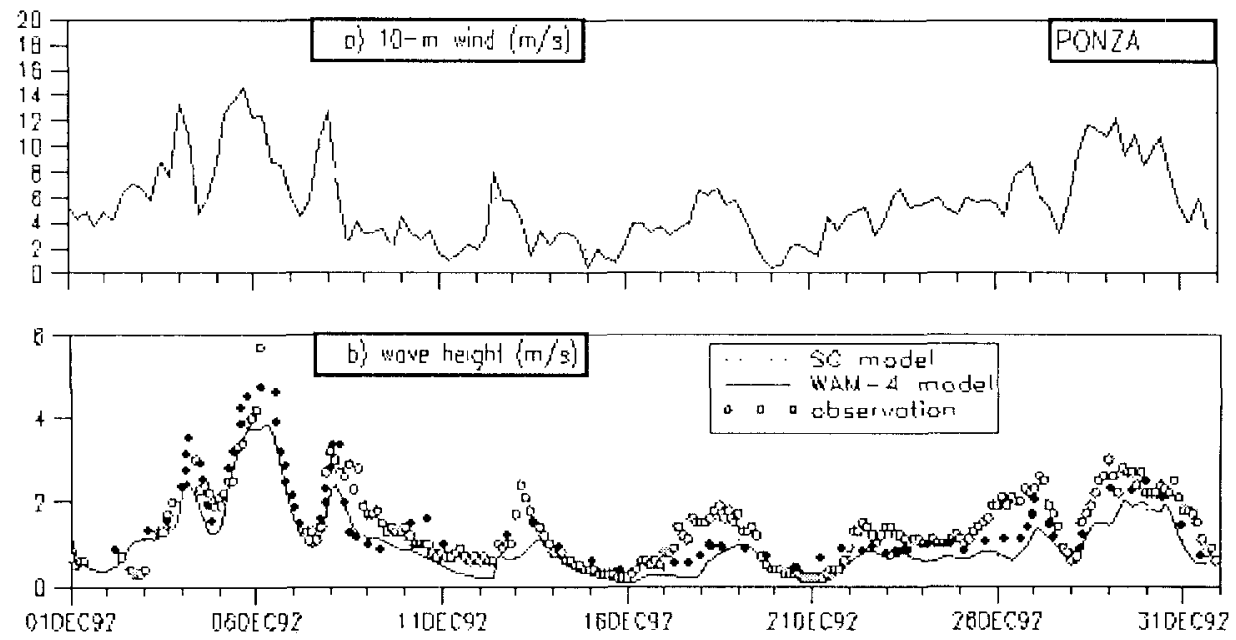

Fig. 10. As in ligure 8 but Pon\%a. 
Fig. 10. As in Figure 8 but Ponza.
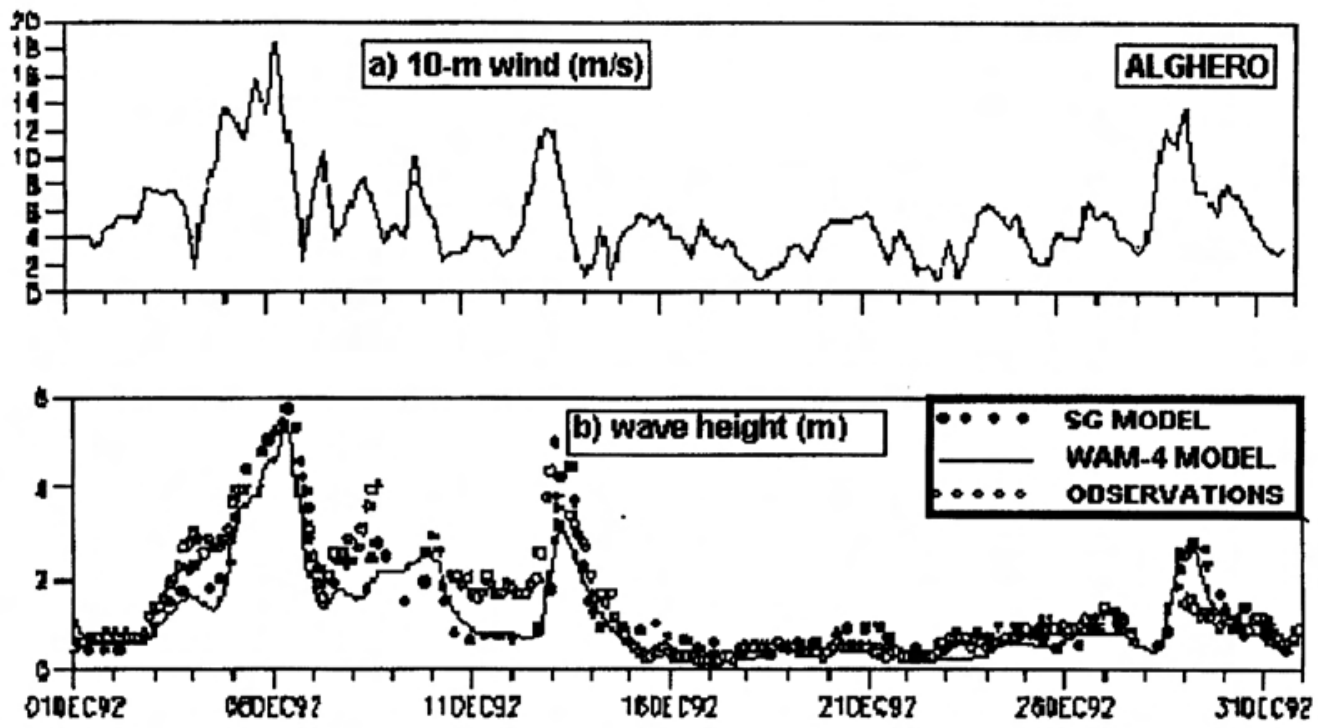

Fig. 11. As in Figure 8, but at Alghero.

Table 2. The root-mean square difference (rmsd) between WAM and bouys (SG and bouys) significant wave heights $\left(\mathrm{H}_{\mathrm{s}}\right)$.

\begin{tabular}{|c|c|c|}
\hline Bouy & $\begin{array}{c}\text { WAM rmsd } \\
(\mathbf{m})\end{array}$ & $\begin{array}{c}\text { SG rmsd } \\
(\mathbf{m})\end{array}$ \\
\hline Alghero (AL) & 0.44 & 0.50 \\
\hline Catania (CA) & 0.51 & 0.49 \\
\hline Crotone (CR) & 0.62 & 0.65 \\
\hline Mazara del Valle (MA) & 0.45 & 0.48 \\
\hline Monopoli (MO) & 0.65 & 0.57 \\
\hline Pescara (PE) & 0.62 & 0.60 \\
\hline Ponza (PO) & 0.50 & 0.52 \\
\hline
\end{tabular}

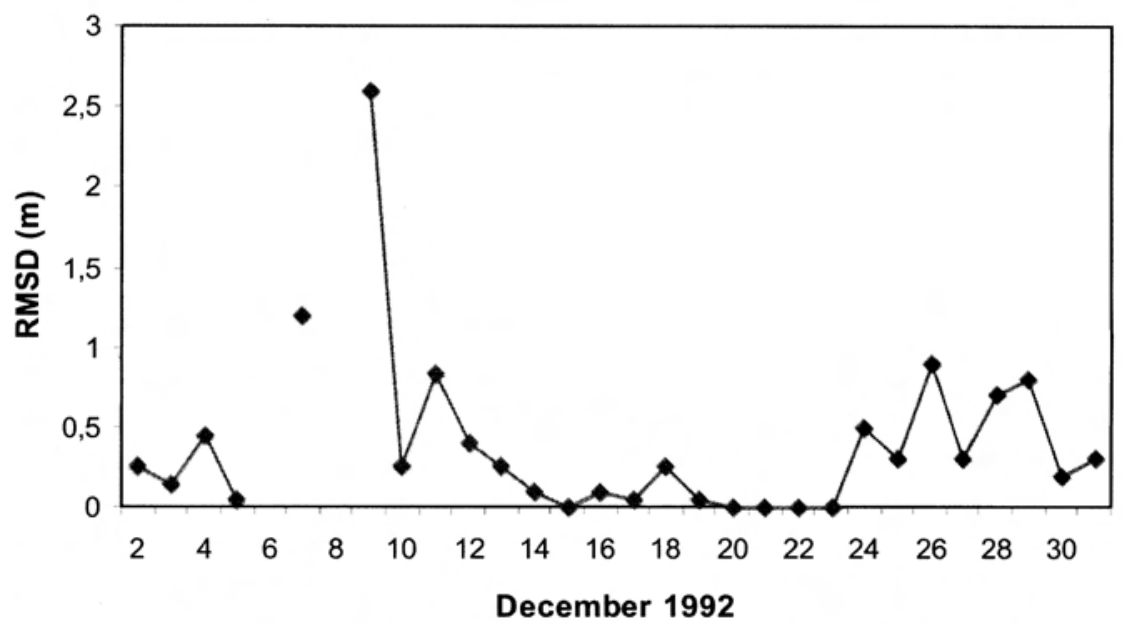

Fig. 12. Temporally varying of the root-mean square difference (rmsd) between the bouy Monopoli (41.5N, 17.5E) and (a) Wam and (b) SG, significant wave height. 


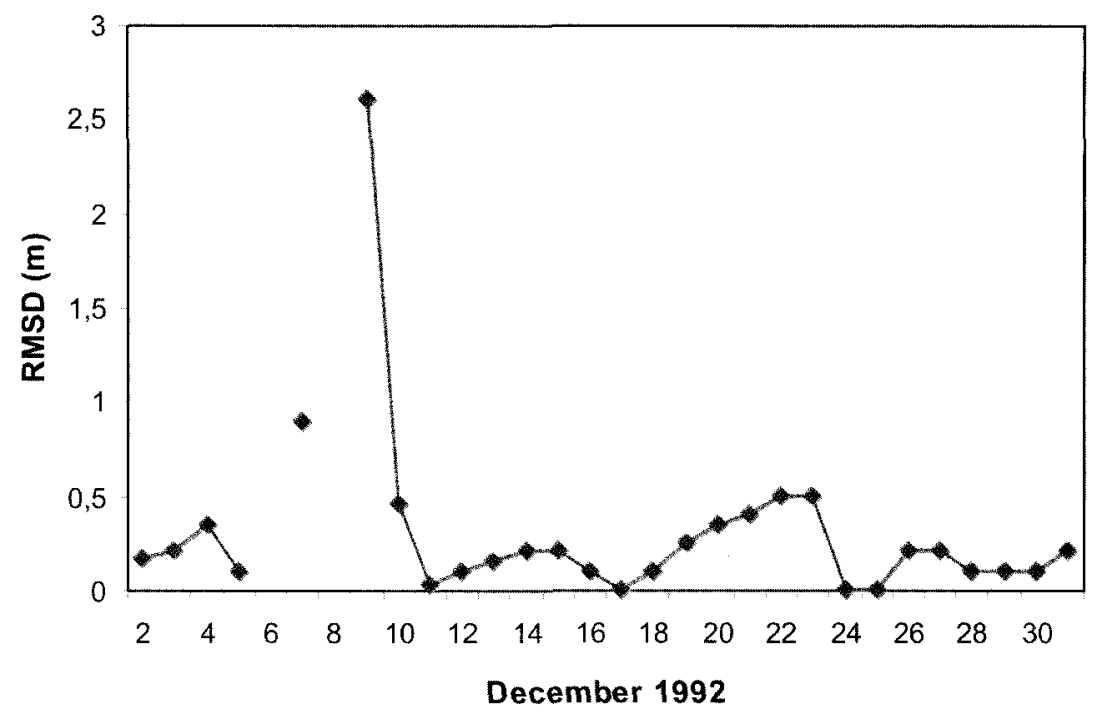

Fig. 12. Cont.

\section{Conclusions}

Second generation wave models suffer from several shortcomings concerning situations with sudden change in wind direction or decrease in wind speed. To overcome these failures, an improved second generation model (SG) is suggested. In this type of model the migration of energy toward the new wind direction and peak frequency is performed slowly, so that the discontinuity between the swell and wind sea tends to take some time to appear in the two-dimensional energy spectrum. This is done by a combination between the present spectrum and that which should be obtained by an abrupt angular relaxation usually employed in a 2 nd generation wave model. In SG the entire spectrum is discretized in frequency and direction. Each spectral component propagates with its own group velocity using a semiLagrangian advection scheme, and is subject to refraction due to the ocean depth variations. The spatial energy is represented in grid points. Generation, dissipation and nonlinear interaction in such way that it fits the empirical Sanders' durationlimited growth curve affect the wind sea

This SG feature is implemented only on the angular relaxation. Based on qualitative arguments, the gradual angular relaxation is performed using a weight function depending on the angle between the wind direction and the direction where the spectrum is being computed. Sine form functions have been chose to satisfy some basic requirements. In future, further tests focusing the specification of the weight function will be carried out through an exact 3 rd generation model and observations. The weight function must be also able to migrate the energy toward the peak frequency smoothly in case of a decreasing wind speed. Most of the idealised experiments shown in S85 are repeated here for a comparative discussion. The results are qualitatively similar to GONO in many aspects. Some discrepancies seem to be caused by the differences in the advection schemes.

The performance of SG and WAM were also compared for Mediterranean Sea using ECMWF wind analyses for the period of December 1992 The temporal and spatial resolutions were of 6 hour and $0.5^{\circ}$, respectively.

The $H_{S}$ time series for a deep ocean point are quite similar in both models simulations during the wave growth stage. However, SG model tends to delay the beginning of the decay stage and simulates wave peaks slightly greater. One episode, where the WAM exhibits a higher $H_{S}$, was an exception. A close examination suggests that a swell was reaching this point. This was confirmed by a small wind speed and great mean wave period. The SG can be adjusted to reproduce the duration-limited curve of WAM, but the discrepancies found in the presence of swell are inherent to second generation models.

On the other hand conclusions regarding the performance of both models in shallow water and coastal zones, where the majority of the buoys are located, cannot be simply stated due to several factors, as instance, appropriate spatial and temporal resolutions and the quality of the wind field. As well established the wave models results dictated by the accuracy the latter.

Encouraged by results of this and other studies (Innocentini \& Caetano Neto, 1996; Rocha et al., 1997, 1998) a weather and sea-wave prediction coupled system is sucessfully running operationally at the Brazilian National Space Institute (Caetano Neto 
\& Innocentini, 1996). This system was implemented in a DEC-ALPHA workstation providing forecasts twice a day for South Atlantic since early 1998. Recently wave and wind data from satellite have become available for the area of interest. The continuous monitoring of these observations and SG results are helping to identify systematic errors, and guiding future improvements and researches.

\section{Acknowledgements}

Sincere thanks to Dr. Hans Hersbach from KNMI, for his assistance in setting up the WAM model in our computational environment and $\mathrm{Mr}$. Luigi Cavaleri from Istituto Studio Dinamica Grandi Masse Venice - Italy, for kindly providing us buoys and ECMWF data. FAPESP Grant 95/4573-5 supported this research.

\section{References}

Allender, J. H: Albrecht, J. \& Hamilton, G. 1983. Observations directional relaxation of wind-sea spectra. J. phys. Oceanogr., 13(8):1519-1525.

Alves, J. H. G. M. \& Melo Filho, E. 1997. Calculation of directional spectra of wind waves through combined fourier transform and maximum entropy methods. Melbourne, IAMAS/IAPSO Joint Assemblies, 1997.

Barnett, T. P. \& Wilkerson, J. C. 1967. On the generation of ocean wind waves as inferred from airborne radar measurements of fetch-limited spectra. J, mar, Res., 25(3):292-328.

Bates, J. R. \& McDonald, A. 1982. Multiplyupstream, semi-lagrangian advective schemes: analysis and application to a multi-level primitive equation model. Mon. Weath. Rev. $110(12): 1831-1842$.

Caetano Neto, E. S.; Innocentini, V. \& Rocha, R. P. da 1996. Um sistema de previsão de tempo e de ondas oceânicas para o Atlântico Sul. Rev. bras. oceanogr., 44(1):35-46.

Carnahan, B.; Luther, H. A. \& Wilkes, J. O. 1969. Applied numerical methods. New York, Wiley. $604 \mathrm{p}$.

Dell'Osso, L.; Bertotti, L. \& Cavaleri; L. 1992. The Gorbush Storm in the Mediterranean Sea: atmospheric and wave simulation. Mon. Weath. Rev., 120(1):77-90.
Earle, M. D. E. 1989. Microcomputer numerical ocean surface wave model. J. atmos. ocean Technol, 6:151-168.

Golding, B. 1983. A wave prediction system for real time sea state forecasting. Q. Jl. R. met. Soc., 109(460):339-416.

Graber, H. C.; Jensen, R. E. \& Cardone, V. J. 1995. Sensitivity of wave model predictions on spatial and temporal resolution of the wind licld. In: INTERNATIONAL WORKSHOP ON WAVE HINDCASTING AND FORECASTING, 4. Banff, Alberta, 1995. Proceedings. p.149-158.

Guillaume, A. 1990. Statistical tests for the comparison of surface gravily wave spectra with application to model validation. J. atmos. ocean Technol., 7(4):551-567.

Gunther, H. \& Rosenthal, W. 1995. Sensitivity of wave model predictions on spatial and temporal resolution of the wind field. In: INTERNATIONAL WORKSHOP ON WAVE IIINDCASTING AND FORECASTING, 4. Banff, Alberta, 1995. Proceedings. p.138-147.

Gunther, H.; Rosenthal, W. \& Dunckel, M. 1981. The response of surface gravity waves to changing wind directions. J. phys. Oceanogr., I 1(5):718728 .

Hasselmann, S. \& Hasselmann, K. 1985 Computations and parameterizations of the nonlinear energy transfer in a gravity wave spectrum. Part 1: a new method for efficient computations of the exact nonlinear transfer integral. J. phys. Oceanogr., 15(11):1369-1377.

Hasselmann, K.; Barnett, T. P.; Bouws, E.; Carlson, H.; Cartwright, D. E.; Enke, K.; Ewing, J. A.; Gicnapp, H.; Hasselmann, D. E.; Druseman, P.; Mccrburg, A.; Müller, P.; Olkers, D.; Richter, K.; Sell. W. \& Walden, H. 1973. Measurements of wind-wave growth and swell decay during the Joint North Sea Wave Project (JONSWAP). Dtsch. IIydrogr. Z., E.A., (12):8-95.

Hasselmann, K.; Ross, D. B.; Müller, P. \& Sell, W. 1976. A parametric wave prediction model. J phys. Oceanogr., 6(2):201-228.

Holthuijsen, L. H.: Kuik, A. J. \& Mosselman, E. 1987. The response of wave directions to changing wind directions. J. phys. Oceanogr., 17(7):845-853 
Innocentini, V. \& Cactano Neto. E. S. 1996. A second generation wave mode: idealized experiments. Ipmet Tecnical Report n. 4. 57p.

Innocentini, V. E. \& Caetano Neto, S. 1996. ^ Case Study of the 9 August 1988 South Atlantic Storm: Numerical simulations of the wave Activity. Weather Forecasting. 11:78-88.

Janssen. P. A. E.; Komen. M. G. J. \& Voogt, W. J. P. de 1984. An operational coupled hybrid wave prediction model. J. geoplys. Res., $89(\mathrm{NC} 3): 3635-3654$.

Komen, G. J.; Cavaleri, L.; Donelan, M.; Hasselmann, K.; Hasselmann, S. \& Janssen, P. A. E. M. 1994. Dynamics and modelling of ocean waves. Cambridge, Cambridge University Press. $532 \mathrm{p}$.

Komen, G. J.: Hasselnamn. S. \& Hasselmann. K. 1984. On the existence of a fully developed windsea spectrum. J. phys. Occanogr., 14(8):12711285.

Masson, D. 1990. Observations of the response of sea waves to veering winds. J. phys. Occanogr., 20(12):1876-1885.

Miles. J. W. 1960. On the generation of waves by turbulent shear flows. J. Fluid Mech., 7(3):469478 .

Phillips, O. M. 1957. On the generation of waves by turbulent wind. J. Fluid Mech., 2(5):417-442.

Rego, V. S. \& Melo Filho, E. 1995. Comparison of monochromatic and spectral wave propagation off the coast of Rio de Janciro. In: INTERNATIONAL CONFLRENCL ON PORI AND COASTAL FNGINEERING IN DEVIELOPING COUNTRIES. Rio de Janeiro, 1995. Proceedings. Rio de Janciro. $\triangle B R H$. p.2048-2062.

Rocha, R. P.; Cactano Neto, E. S. \& Innocentini, V. 1997. Ocorrência de ondas intensas na Bacia de Campos após a passagem de uma frente fria: estudo do caso de 24 a 27 de julho de 1988 Pesquisa Naval, 9:215-248.
Rocha, R. P.: Caetano Neto, F. S. \& Innocentini, V. 1998. Estudo do Evento 09 a 13 de junho de 1989 no Atlântico Sul: simulações numéricas da atmosfera e da agitação marítima. Pesquisa Naval, $11: 279-297$.

Sanders, J. W. 1976. A growth-stage scaling model for the wind-driven sea. Dt. Hydrog. Z. 29:136161.

Sanders, J. W.: Voogt. W. J. de \& Bruinsma. J. 1981. Fysich gol-fonderzoek noordzee. Sei. Rep. MLTP-2. Raal Overleg Fys. Oceanogr. Onderz.

The SWAMP Group 1985. Ocean wave modeling. Principal results of a wave intercomparison study conducted by the sea wave modeling (SWAMP) and lirst presented at a symposium on wave dynamics an radio probing of the ocean surface, Miami, Florida. New York. Plenum Press. 256p.

The WAMDI Group (1988). The WAM model ‥ a third generation ocean waves prediction model. J. phys. Occanogr., 18:1775-1810.

Van Vledder, G. P. \& Holthuijsen, L. H. 1993. The directional response of ocean waves to tuming winds. J. phys. Oceanogr., 23(2):177-192.

Young, I. R.; Hasselmann, S. \& Hasselmann, K. 1987. Computations of the response of a wave spectrum to a sudden cliange in the wind direction. J. phys. Oceanogr., 17(9):1317-1338.

Young, I. R. \& Sobey, R. J. 1985. Measurements of the wind-wave flux in na opposing wind. J. Fluid Mech., 151:427-442.

(Mamuscript received 18 June 2001; revised 02 July 2002; aceepled 18 December 2002) 